\title{
Multiple Roles and Effects of a Novel Trichoderma Hydrophobin
}

\author{
Michelina Ruocco, ${ }^{1}$ Stefania Lanzuise, ${ }^{2}$ Nadia Lombardi,,${ }^{1,2}$ Sheridan L. Woo, ${ }^{1,2}$ Francesco Vinale, ${ }^{1}$ \\ Roberta Marra, ${ }^{2}$ Rosaria Varlese, ${ }^{2}$ Gelsomina Manganiello, ${ }^{2}$ Alberto Pascale, ${ }^{2}$ Valeria Scala, ${ }^{3}$ David Turrà, ${ }^{4}$ \\ Felice Scala, ${ }^{1,2}$ and Matteo Lorito ${ }^{1,2}$
}

${ }^{1}$ Consiglio Nazionale delle Ricerche, Istituto per la Protezione Sostenibile delle Piante Portici, Napoli, Italy; ${ }^{2}$ Università degli Studi di Napoli "Federico II", Dipartimento di Agraria, Portici, Napoli, Italy; ${ }^{3}$ Università La Sapienza, Dipartimento di Biologia Ambientale, Roma, Italy; ${ }^{4}$ University of Cordoba, Department of Genetics, E-14071 Cordoba, Spain

Submitted 2 July 2014. Accepted 6 October 2014.

Fungi belonging to the genus Trichoderma are among the most active and ecologically successful microbes found in natural environments, because they are able to use a variety of substrates and affect the growth of other microbes and virtually any plant species. We isolated and characterized a novel type II hydrophobin secreted by the biocontrol strain MK1 of Trichoderma longibrachiatum. The corresponding gene (Hytlo1) has a multiple role in the Trichoderma-plantpathogen three-way interaction, while the purified protein displayed a direct antifungal as well as a microbe-associated molecular pattern and a plant growth promotion (PGP) activity. Leaf infiltration with the hydrophobin systemically increased resistance to pathogens and activated defense-related responses involving reactive oxygen species, superoxide dismutase, oxylipin, phytoalexin, and pathogenesis-related protein formation or activity. The hydrophobin was found to enhance development of a variety of plants when applied at very low doses. It particularly stimulated root formation and growth, as demonstrated also by transient expression of the encoding gene in tobacco and tomato. Targeted knock-out of Hytlo1 significantly reduced both antagonistic and PGP effect of the wild-type strain. We conclude that this protein represents a clear example of a molecular factor developed by Trichoderma spp. to establish a mutually beneficial interaction with the colonized plant.

Fungi of the genus Trichoderma are widely known for their activity as pathogen killers and inhibitors, disease suppressor and resistance stimulators (Harman et al. 2004; Seidl et al. 2006a; Shoresh et al. 2010) growth promoters, sources of useful genes and compounds (Lorito et al. 2010; Vinale et al. 2008), soil cleaners and enrichers, and commercially successful integrated pest management (IPM) tools (Lorito and Woo 2014). Many Trichoderma spp. may have ancestrally evolved as predators (Druzhinina et al. 2011) and still use different mycoparasitic strategies (Atanasova et al. 2013). However, an increasing number of genetic characters somehow related to a mutual beneficial interaction with plants have been identified in the

Corresponding authors: M. Ruocco; E-mail: ruocco@ipp.cnr.it; and M. Lorito; E-mail: lorito@unina.it

* The $\boldsymbol{e}$-Xtra logo stands for "electronic extra" and indicates that three supplementary figures are published online.

(C) 2015 The American Phytopathological Society last couple of decades (Hermosa et al. 2012). Two typical direct effects on the plant have been extensively found also in field applications: systemic enhancement of disease resistance and growth promotion (Vos et al. 2014). Activation of either induced systemic resistance (ISR) or systemic acquired resistance pathways, or both, has been reported for strains belonging to different species on a variety of plants (Segarra et al. 2009; Velazquez-Robledo et al. 2011; Yoshioka et al. 2012), although the mechanism is still not fully understood. The involvement of both microbe-associated molecular patterns (MAMPs) (proteins, sugars, and secondary metabolites) or elicitors recognized by specific receptors (Avni et al. 1994) and defense-related hormones (Martinez-Medina et al. 2013) has been demonstrated. Plant response to pathogens, modified by Trichoderma spp., corresponds to a differential expression of dozens of genes (Alizadeh et al. 2013; Mastouri et al. 2012; Tucci et al. 2011), may include a priming status (ISR-prime and ISR-boost phase) (Brotman et al. 2012; Conrath et al. 2006; Perazzolli et al. 2011; Tucci et al. 2011; Vos et al. 2014), and could result in enhanced pathogen-associated molecular pattern-triggered immunity and effector-triggered immunity (Lorito et al. 2010). Fungal molecules found to be involved include i) enzymes such as cellulases and xylanases (Collen et al. 2005; Martinez et al. 2001), although the catalytic activity may be unrelated to the elicitation property (FurmanMatarasso et al. 1999; Rotblat et al. 2002); ii) other proteins such as the Trichoderma virens 18-kDa serine protease (Hanson and Howell 2004) or SM1, EPL1, and EPLT4, secreted by $T$. virens, T. atroviride, and T. asperellum, respectively (Djonovic et al. 2006; Seidl et al. 2006a,b; Vargas et al. 2008; Wang et al. 2013a); iii) a $T$. asperellum swollenin also supporting root colonization (Brotman et al. 2008); and iv) secondary metabolites such as the 6-pentyl- $\alpha$-pyrone and harzianolide (Malmierca et al. 2012; Vinale et al. 2012). In contrast, much less is known about the molecular factors eventually supporting the Trichoderma plant growth promotion (PGP) activity. The outcome, which can be strongly dependent on the plant genotype (Tucci et al. 2011), may include enhancement of plant size, root system, stem length and thickness, leaf area, chlorophyll content, size or number of flowers or fruit, and yield. These effects may be due to improved nutrient availability (Altomare et al. 1999) or production by the fungus of phytohormons or molecules acting as such (Qi and Zhao 2013; Vinale et al. 2009; Zhang et al. 2013) or substrate detoxification (Caporale et al. 2014).

The near ubiquitous filamentous fungi hydrophobins are among the most active surface or secreted proteins known (Linder et al. 2005). They are classified on the basis of chemi- 
cal properties (hydrophobicity and solubility) into two classes (Wessels 1999), where the class II hydrophobins have a degree of solubility in water much higher than those of class I, especially in the presence of ethanol or sodium dodecyl sulfate (SDS) (Wang et al. 2013b). In most cases, these proteins have been found to support developmental processes, including the formation of aerial hyphae, spores, and fruiting bodies (Whiteford and Spanu 2002; Wosten 2001). However, several hydrophobic proteins and peptides, isolated from fungi, have been shown to affect plant development (i.e., QID74 of Trichoderma spp.) (Samolski et al. 2012), resistance to disease (i.e., SM1, EPL1, and EPLT4, all from Trichoderma spp.) (Djonovic et al. 2006; Seidl et al. 2006b; Wang et al. 2013a), or health (i.e., cerato-ulmin and members of the cerato-platanin family) (Baccelli et al. 2014; Martellini et al. 2013). In addition, fungal hydrophobins are known to be involved in the plant-ectomycorrhiza interaction which, to a certain extent, may resemble the Trichoderma-plant interaction (Acioli-Santos et al. 2008; Tagu and Martin 1996).

In this article, we present a novel 7.2-kD hydrophobin constitutively secreted by $T$. longibrachiatum, and the evidence that it has multiple roles in the fungus and different effects both on plants and other microbes, including direct inhibition, ISR, and growth promotion. Our data suggest that this protein, which may be related to peptides with similar properties found in other Trichoderma spp., may represent an example of a factor specifically developed by rhizosphere-colonizing fungi to support a mutually beneficial interaction with plant roots.

\section{RESULTS}

Purification and characterization.

The search for MAMPs with chitin-binding ability (van den Burg et al. 2003, 2006) in the low molecular weight secre-

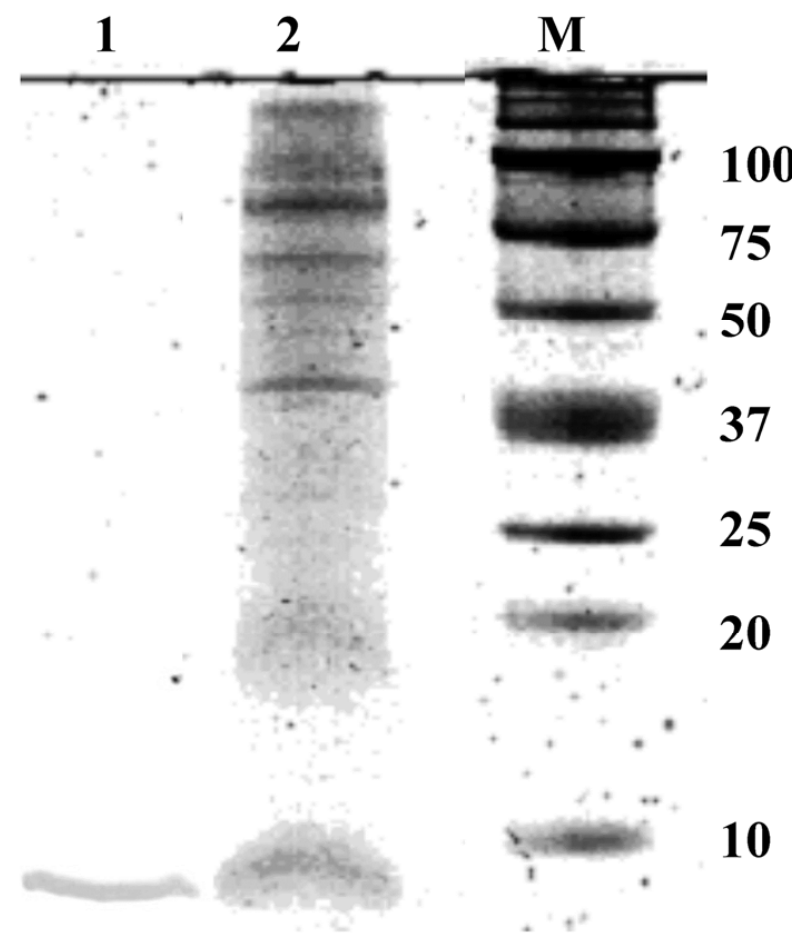

Fig. 1. Silver-stained sodium dodecyl sulfate polyacrylamide gel electrophoresis of HYTLO1 hydrophobin from Trichoderma longibrachiatum extracted from culture filtrate obtained by growing the fungus on Murashige and Skoog (MS) amended with plant tissue. Lane 1, pure HYTLO1 from T. longibrachiatum; lane 2, total protein (secreted) extract from T. longibrachiatum culture filtrate; lane $\mathrm{M}$, molecular weight markers in kilodaltons. tome of the T. longibrachiatum biocontrol strain MK1 revealed a protein of about $8 \mathrm{kDa}$ (Fig. 1) profusely produced when the fungus was grown in salt liquid media enriched, as the only carbon source, with plant tissue, fungal biomass, or cellulose. Sequencing of the $\mathrm{N}^{\prime}$ terminal followed by a $3^{\prime}$ random amplification of cDNA ends (RACE) resulted in identification of a gene encoding a class II hydrophobin (Supplementary Fig. S1) from various fungi, including T. reesei, T. harzianum, T. virens, T. atroviride, Claviceps purpurea, and Metarhizium anisopliae. The new gene was named Hytlol (accession number EF419429, originally named Hytral). Its cDNA sequence was $216 \mathrm{bp}$ long, while the predicted protein had 71 amino acids, with eight cysteine residues arranged in the strictly conserved hydrophobin motif $\mathrm{X}_{\mathrm{n}}-\mathrm{C}-\mathrm{X}_{5-10^{-}} \mathrm{C}-\mathrm{C}-\mathrm{X}_{11-44^{-}}$ $\mathrm{C}-\mathrm{X}_{8-23}-\mathrm{C}-\mathrm{X}_{5-9}-\mathrm{C}-\mathrm{C}-\mathrm{X}_{6-18}-\mathrm{C}-\mathrm{X}_{\mathrm{m}}$, and a molecular weight of $7,218 \mathrm{Da}$. The genomic copy, obtained by polymerase chain reaction (PCR), was $361 \mathrm{bp}$ and contained two introns of 72 and $73 \mathrm{bp}$. Southern analysis indicated the presence of a single copy of Hytlol in the genome of T. longibrachiatum MK1 (Fig. 2). Northern analysis showed that the expression of this gene was both constitutive and particularly stimulated by growing the fungus in Murashige and Skoog (MS) medium with $1 \%$ cellulose, $1 \%$ chitin, or $1 \%$ tomato tissue extracts. Interestingly, the presence of Rhizoctonia solani cell walls or culture filtrate decreased Hytlol expression (Fig. 3). Purification of HYTLO1 from culture filtrate of T. longibrachiatum was obtained by growing the fungus for 7 days in liquid MS, with a yield of $15 \mathrm{mg} /$ liter of culture. In this study, genomic sequences reacting with the Hytlol probe (entire se-

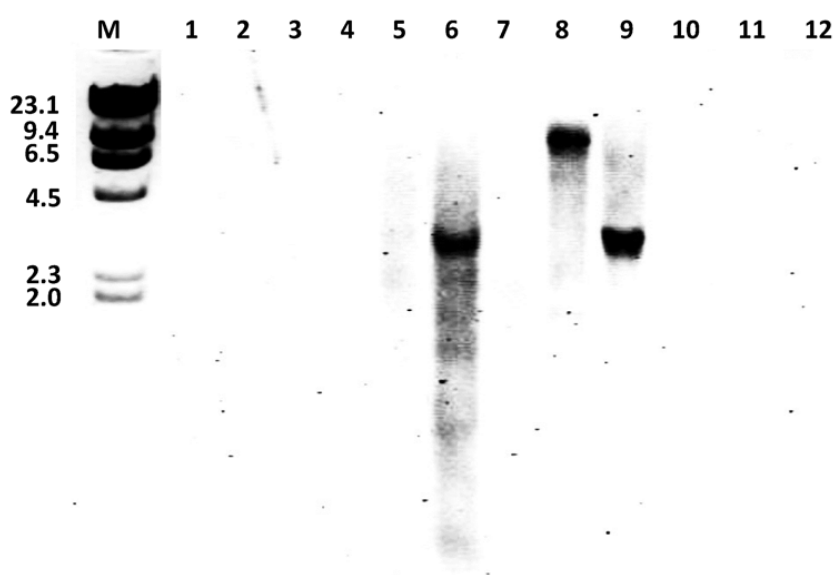

Fig. 2. Southern analysis of different Trichoderma spp. by using the Hytlol hydrophobin gene as a probe (entire genomic sequence). Lane 1, Trichoderma virens; lane 2, T. reesei; lane 3, T. gelatinosa; lane 4, T. hamatum; lane 5, T. harzianum; lane 6, T. minutisporum; lane 7, T. viride; lane 8, T. aggressivum; lane 9, T. longibrachiatum; lane 10, T. atroviride; lane 11, T. strictipile; and lane 12, T. brevicompactum.

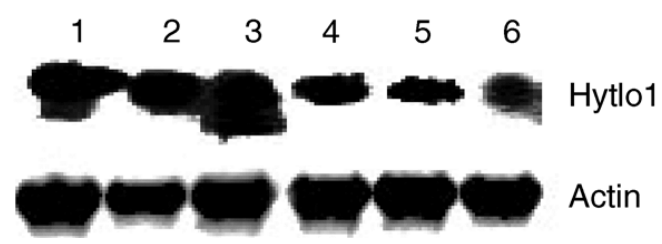

Fig. 3. Expression of Hytlo1 gene from Trichoderma longibrachiatum MK1 in the presence of different carbon sources, plant pathogen culture filtrates (CFs), or cell wall. Lane 1, Murashige and Skoog (MS) $+1 \%$ (wt/vol) cellulose; lane 2, MS+ $1 \%(\mathrm{wt} / \mathrm{vol})$ chitin; lane $3, \mathrm{MS}+1 \%$ (wt/vol) tomato leaves; lane $4, \mathrm{MS}+1 \%$ (vol/vol) Rhizoctonia solani $\mathrm{CF}$; lane $5, \mathrm{MS}+1 \%(\mathrm{wt} / \mathrm{vol}) \mathrm{R}$. solani cell walls; and lane $6, \mathrm{MS}+1 \%$ (wt/vol) sucrose. 
quence) were found only in T. minutisporum and T. aggressivum among 12 species of Trichoderma tested by Southern analysis (Fig. 2).

\section{Direct antifungal activity.}

Purified HYTLO1was able to directly inhibit both spore germination and hyphal elongation of Botrytis cinerea and Alternaria alternata in vitro even when used at very low concentration (starting at $1 \mu \mathrm{M}$ ), with no apparent effects on $T$. longibrachiatum (Fig. 4A). Interestingly, type II hydrophobins purified by using the same methods from two strains of $T$. harzianum did not show the same inhibitory effect (Fig. 4B). Antifungal activity was found when the protein was either dispersed in the liquid or incorporated into an agarized growth medium.

\section{Plant protection effect.}

Co-application of purified HYTLO1 and $B$. cinerea on tomato leaves significantly reduced or almost completely blocked the appearance of symptoms when the protein was used at a rate of $2.5 \mu \mathrm{M}$ or more in the treating solution applied as a spray (Fig. 5). A similar effect was recorded on cucumber, sweet pepper, and zucchini challenged also with $B$. cinerea (data not shown). In terms of systemic enhancement of disease resistance, HYTLO1 was able to significantly reduce lesions caused by this pathogen when infiltrated at a rate of $2.5 \mu \mathrm{M}$ in distal leaves (Fig. 6A). If the hydrophobin was applied as a spray treatment to the basal leaves of plants challenged with
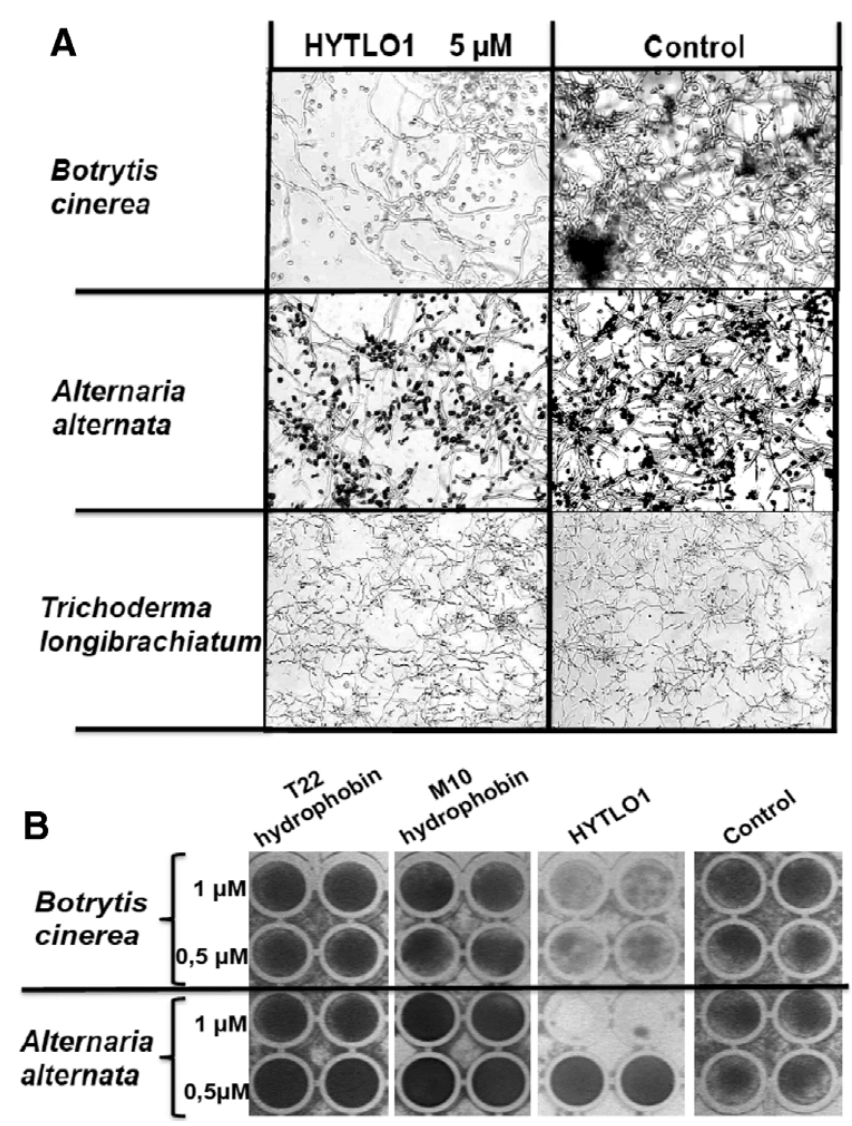

Fig. 4. Direct antifungal activity of HYTLO1 hydrophobin from Trichoderma longibrachiatum. Inhibition of Botrytis cinerea and Alternaria alternata observed in $\mathbf{A}$, axenic liquid cultures and $\mathbf{B}$, enzyme-linked immunosorbent assay plates. In the latter case, lightly colored versus dark spots (fully grown fungal colony may tend to melanize) indicate an inhibitory effect, determined also by comparing HYTLO1 with two similar hydrophobins extracted from T. harzianum strains T22 and M10.
$B$. cinerea on the upper leaves, the difference with the control was less remarkable (Fig. 6B). However, the reduction of symptom development was more pronounced if plants were seed-treated with the biocontrol strain T22 of T. harzianum

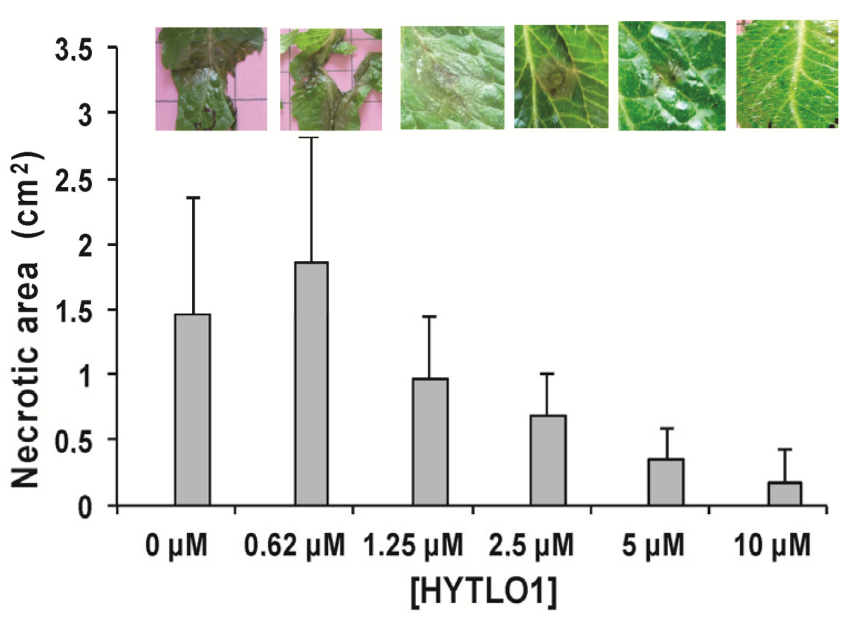

Fig. 5. Effect of HYTLO1 application on the lesion development on tomato leaves challenged with the pathogen Botrytis cinerea. For each concentration, $10 \mu \mathrm{l}$ of pure HYTLO1 was applied on tomato leaves and, after $2 \mathrm{~h}, 10 \mu \mathrm{l}$ of a $B$. cinerea spore suspension $\left(1 \times 10^{6}\right.$ spores $\left./ \mathrm{ml}\right)$ was applied at the same point. Measures were taken $72 \mathrm{~h}$ postinoculation. Values are means of at least three different experiments, with five replicates and a total of 15 leaves used per treatment. Bars indicate standard deviations.

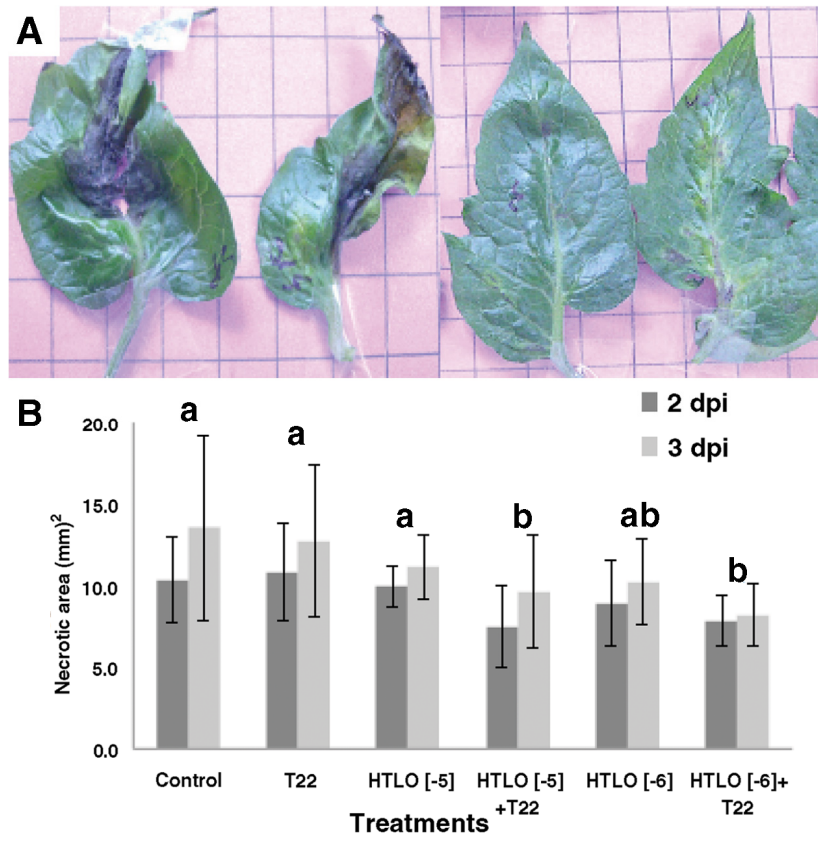

Fig. 6. Effect of HYTLO1 application, alone or in combination with Trichoderma harzianum T22, on the induction of systemic resistance in tomato and pepper. A, Tomato plants were leaf-infiltrated with $10 \mu \mathrm{l}$ of a $2.5-\mu \mathrm{M}$ water solution of the hydrophobin and lesion development was evaluated on distal, not treated leaves. Treated and control leaves are the two on the right and the two on the left, respectively. B, Sweet pepper plants were sprayed on the basal leaves with a HYTLO1 water solution at two different concentrations $\left(10^{-5}\right.$ and $10^{-6} \mathrm{M}=-5$ and -6 in the graph), and inoculated after $24 \mathrm{~h}$ with $10 \mu \mathrm{l}$ of a Botrytis cinerea spore suspension at $1 \times 10^{6} / \mathrm{ml}$ on the upper leaves. For treatment with T22, seed were soaked in a $1 \times 10^{7}$ spore $/ \mathrm{ml}$ suspension of the fungus and allowed to dry before seeding. Size of necrotic area were determined 2 and 3 days postinoculation (dpi). Values are means of at least three different experiments, with five replicates and a total of 15 leaves used per treatment. Bars indicate standard deviations. For each group, different letters indicate a significant difference $(P<0.001)$. 
(Fig. 6B), a fungus that yielded a type II hydrophobin lacking the direct antifungal activity shown by HYTLO1 (Fig. 4B).

\section{PGP effect.}

Purified HYTLO1 was able to generally enhance plant growth by affecting seed germination, plantlet development, stem size, root and leaf formation, and so on. The application rate used determined the nature (positive or negative) of the effect on the germination of tomato seed, with a partial or total inhibition when the protein was applied at a concentration in the media higher than $0.31 \mu \mathrm{M}$ (up to $10 \mu \mathrm{M}$ were tested) and an enhancement of germination when it was used at 0.31 to $0.1 \mu \mathrm{M}$ (data not shown). The same results were obtained when the effect on seedling development was determined (Fig. 7A). Soaking of a tomato plantlet in a HYTLO1 $0.01 \mu \mathrm{M}$ water solutions generally resulted in enhanced root development (Fig. 7B). Furthermore, formation of new roots was stimulated when tomato stem cuttings where treated with the fungal hydrophobin at $0.31,0.075$, or $0.018 \mu \mathrm{M}$ concentration (Fig. 7C). Application of HYTLO1 (0.01 $\mu \mathrm{M}$ water solution) to tomato plants strongly promoted growth both below ground and above ground in sterilized soil (Fig. 8). Spraying versus drenching produced the best results, with an obtained increase of about 50 to over $100 \%$ of plant height, root length, number of leaves, stem diameter, and total fresh weight compared with water-treated controls (Fig. 8). Interestingly, the spray application of the hydrophobin was more effective than the treatment with the HYTLO1-producing strain MK1 (Fig. 8).

In another experiment performed in natural, unsterilized soil, HYTLO1 applied as drenching produced a constant increase in tomato plant height, root length, root and stem fresh weight, and root and stem dry weight not only versus treatment with water but also in comparison with the commercial formulation of T. harzianum T22 or an auxin-based commercial product, Germon-E (Fig. 9). Purified HYTLO1 displayed a PGP effect also on Arabidopsis, cucumber, Lotus japonicus, and artichoke plants, as tested in vitro or in vivo (Fig. 10).

\section{Plant molecular response.}

The purified $T$. longibrachiatum hydrophobin produced a strong biochemical response when injected into tomato leaves as a $10-\mu$ l water solution, depending on the dose used (from 0.31 to $10 \mu \mathrm{M}$ ). Macroscopically, HYTLO1 applied at 0.31 , 0.62 , and $1.25 \mu \mathrm{M}$ produced no response up to $96 \mathrm{~h}$ postinjection (hpi) (Fig. 11A). Concentrations of 2.5 and $5.0 \mu \mathrm{M}$ only

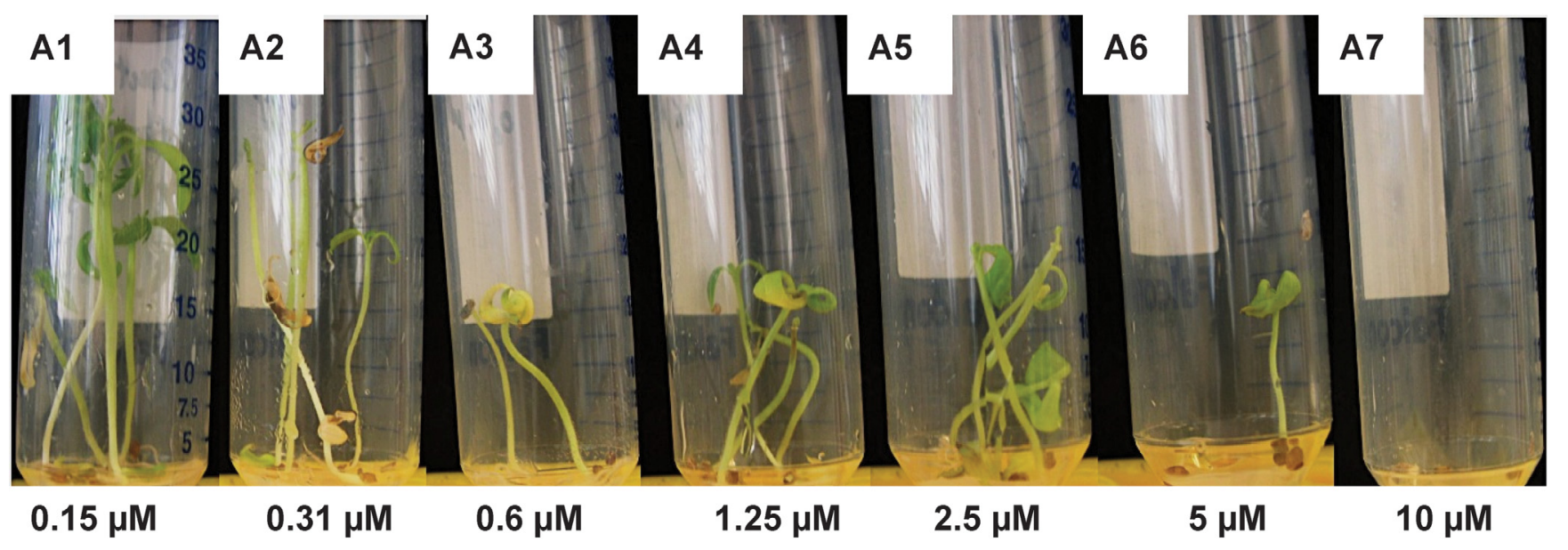

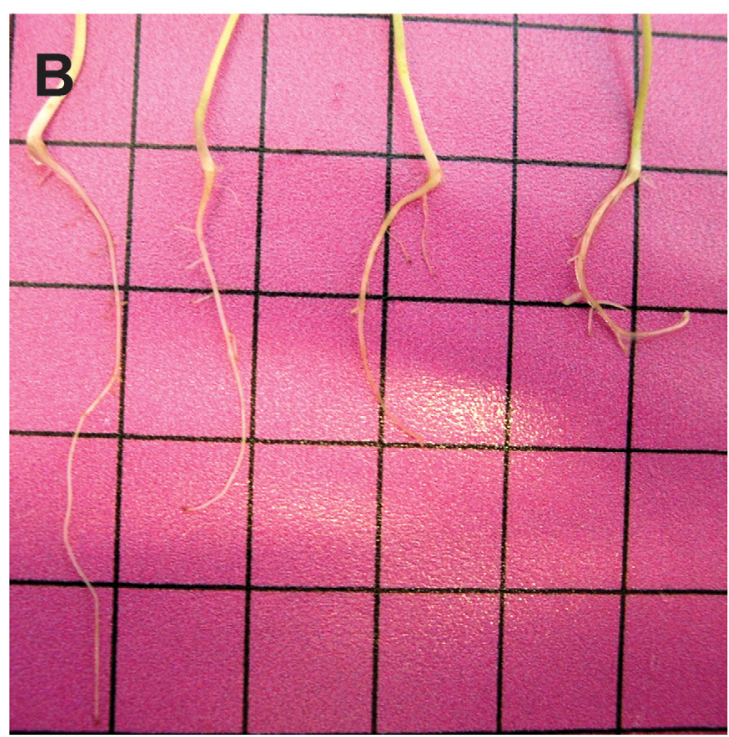

Control

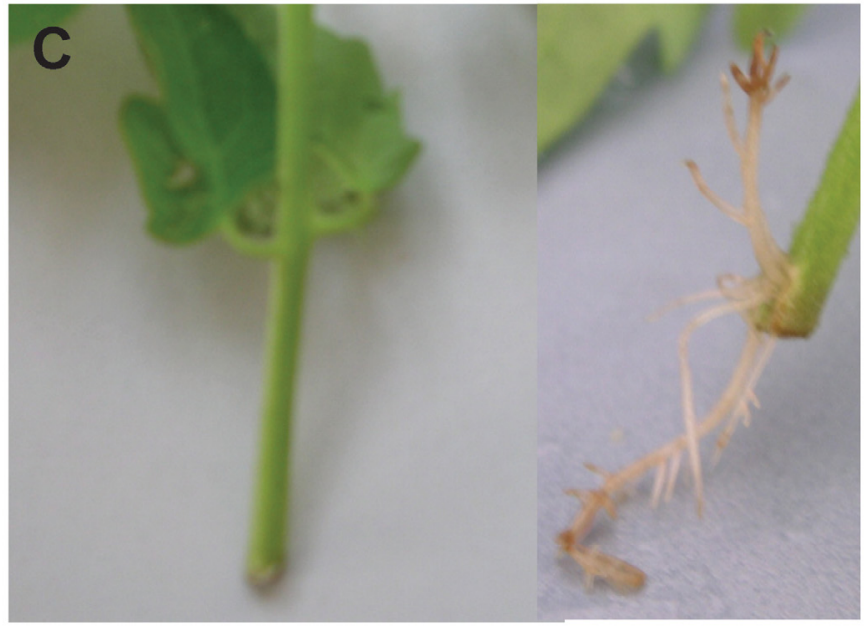

\section{Control}

Fig. 7. Effect of purified HYTLO1 application to tomato seedling development and rooting. A, Trichoderma longibrachiatum hydrophobin was incorporated into the agarized medium at the indicated concentration. B, Roots were dipped into a HYTLO1 solution at $0.01 \mu \mathrm{M}$. C, Tomato stem cuttings soaked in a $0.018-\mu \mathrm{M}$ hydrophobin solution versus water-treated control. 
caused a strong auto-fluorescence under UV light starting from 12 hpi (Fig. 11B and C). HYTLO1 at $5 \mu \mathrm{M}$ generated necrotic spots at 96 hpi (Fig. 11D), while treatment with $10 \mu \mathrm{M}$ produced a strong necrogenic reaction, possibly due to an exten- sive hypersensitive response (HR), and a clear autofluorescence already at 24 hpi (Fig. 11E). Leaf injection of HYTLO1 generally stimulated the activation of defense-related responses, including reactive oxygen species (ROS), superoxide dismu-

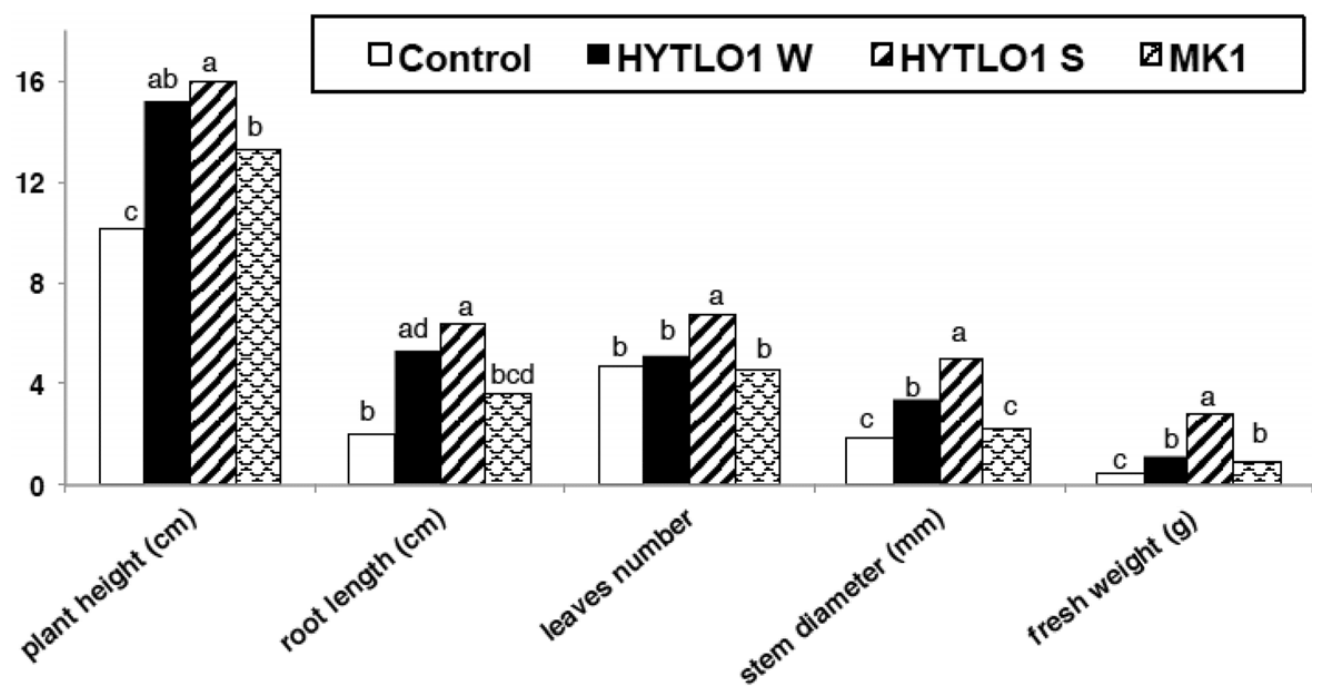

Fig. 8. Effect of Trichoderma longibrachiatum HYTLO1 applied ectopically on tomato plants. Plants were sprayed (HYTLO1 S) or watered (HYTLO1 W) with a $0.01-\mu \mathrm{M}$ solution of the hydrophobin or watered with a $1 \times 10^{7} \mathrm{spore} / \mathrm{ml}$ suspension of T. longibrachiatum MK1 weekly for 1 month. Control plants were sprayed or watered with sterile water. Values are means form at least three different experiments. For each group, different letters indicate a significant difference $(P<0.001)$.


Fig. 9. A to C, Effect of HYTLO1 treatment on the growth of tomato cuttings compared with Trichoderma harzianum T22 and the commercial hormone (NAA) formulation Germon-E (Gr-E) (L. Gobbi s.r.l., Genova, Italy). Tomato cuttings were soaked in T. harzianum T22 spore suspension, Germon-E, 0.01 $\mu \mathrm{M}$ HYTLO1 water solution or B, $0.01 \mu \mathrm{M}$ HYTLO1 water solution in combination with Germon-E. In A, Percentage of increase was obtained by using HYTLO1 versus the indicated treatment. 
tase (SOD), oxylipin, phytoalexin, and pathogenesis-related (PR) protein formation or activity (Figs. 12 and 13).

Superoxide anion production was rapidly enhanced by the fungal hydrophobin in the treated leaves although, after an early peak, the ROS level decreased to that of the control (Fig. 12A). HYTLO1 at 0.15 and $2.5 \mu \mathrm{M}$ increased the $\mathrm{O}_{2}^{-}$amount to a level that remained constant for up to $48 \mathrm{hpi}$ or progressively increased in time, respectively (Fig. 12A). Instead, HYTLO1 5.0 $\mu \mathrm{M}$ caused a strong early reaction that, however, totally dissipated between 6 and 24 hpi (Fig. 12A). Activation of SODc at pH 7.8 (putatively cytosolic) and SODp at pH 10.0 (putatively peroxisomal) in response to ROS accumulation was also stimulated by the treatment, mainly 48 hpi with the protein applied at $2.5 \mu \mathrm{M}$ (Figs. $12 \mathrm{~B}$ and $\mathrm{C}$ ). No effect on $\mathrm{O}_{2}^{-}$accumulation and SOD activity was found in distal leaves (data not shown). Concentration of peroxides (R-OOH), as related to a typical oxidative burst reaction, was systemically increased by HYTLO1, especially when the hydrophobin was applied at the lower dose, in both the treated and distal leaves (Fig. 12D and E). Trichoderma MK1 hydrophobin also activated lipoxygenase (LOX) in treated (Fig. 12F and G) but not in distal leaves (data not shown). In particular, some products of LOX activity (namely, 9- and 13-H(P)ODE), known to be related to stress, jasmonate synthesis, and HR (Montillet et al. 2004),



Control
B

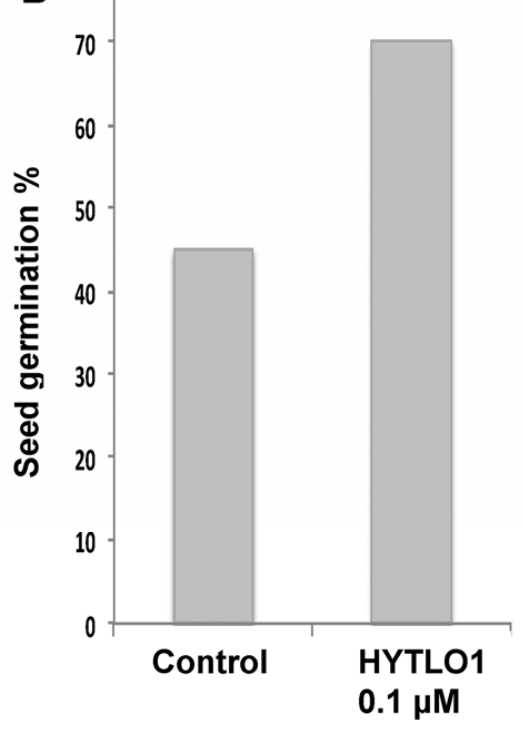

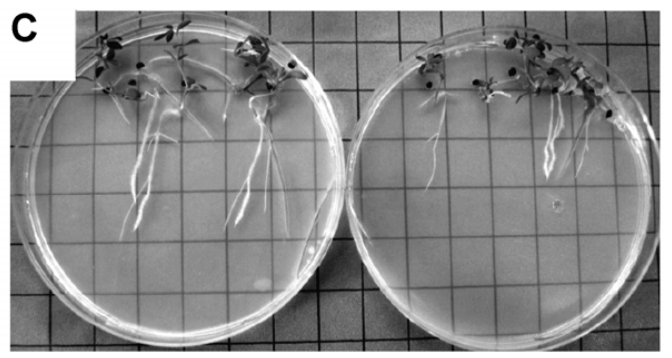

HYTLO1 $0.1 \mu \mathrm{M}$

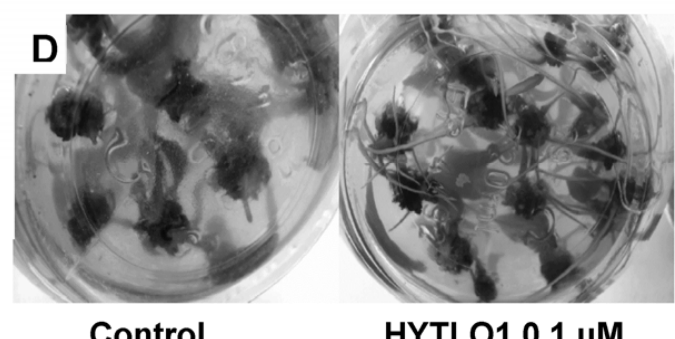

Fig. 10. Plant growth promotion effect of HYTLO1 on A, Arabidopsis growth and $\mathbf{B}$, seed germination and of root development of $\mathbf{C}$, Lotus japonicum and D, artichoke plants. HYTLO1 was applied by root irrigation (A and B) or incorporated into the medium (C and D).
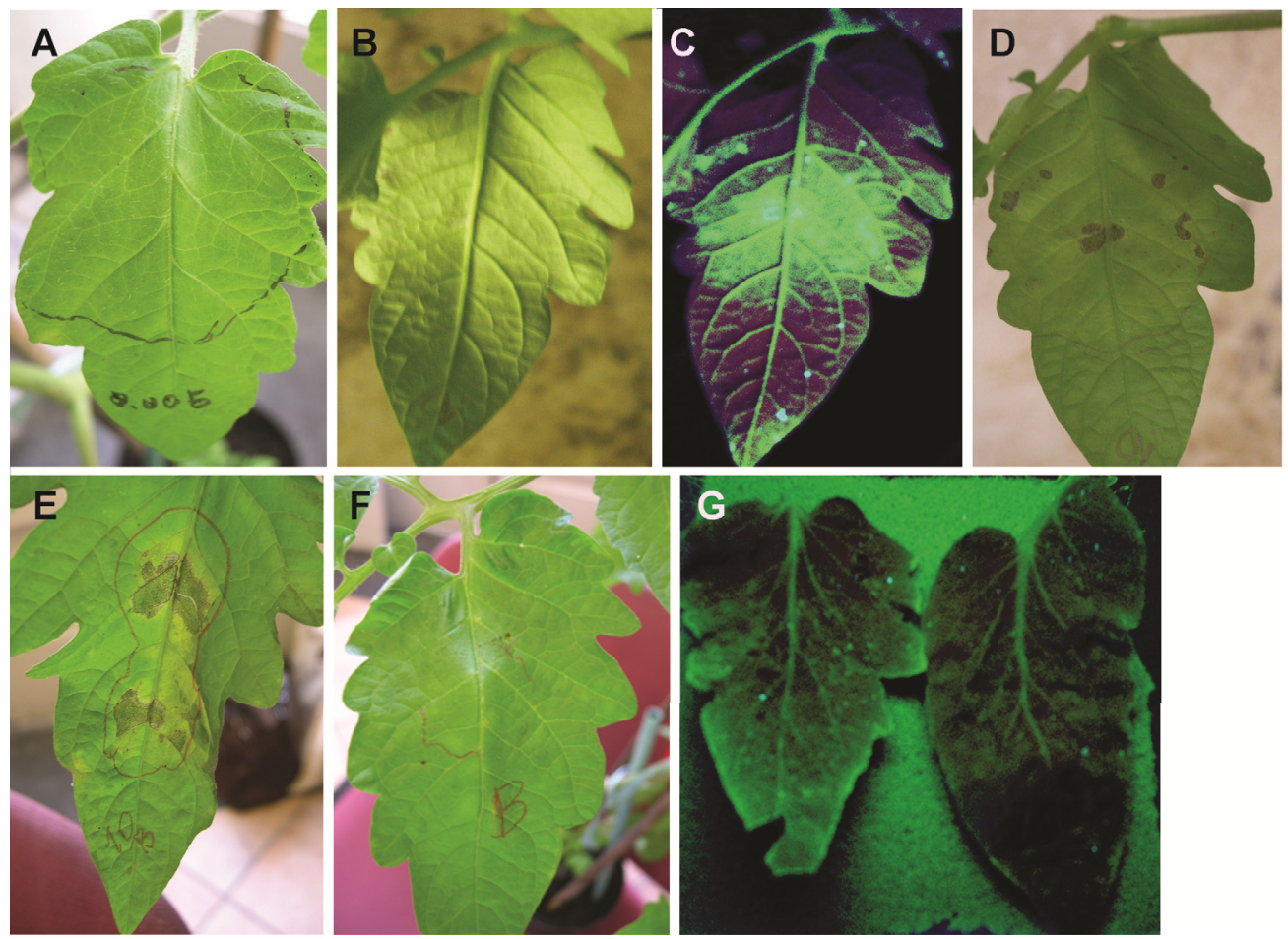

Fig. 11. Response of tomato leaves injected with purified HYTLO1 solution of Trichoderma longibrachiatum, Images show accumulation of fluorescent defense-related compounds and necrotic plus chlorotic reactions. The hydrophobin was used at $\mathbf{A}, 1.25 \mu \mathrm{M}$ ( $96 \mathrm{~h}$ postinoculation [hpi]); $\mathbf{B}$ and $\mathbf{C}, 2.5 \mu \mathrm{M}$ (12 hpi); D, $5.0 \mu \mathrm{M}$ (96 hpi); or E, $10 \mu \mathrm{M}$ (24 hpi). Effect on control leaves injected with the solvent at 96 hpi F, under visible light and G, under UV light). 
were positively affected at 24 and 48 hpi when HYTLO1 was used at a concentration of at least $2.5 \mu \mathrm{M}$ (Fig. 12G). The production of the phytoalexin rishitin appeared also to be stimulated on injected leaves 24 and $48 \mathrm{hpi}$, particularly if the hydrophobin was applied at $2.5 \mu \mathrm{M}$ (Fig. 12H), which is the same treatment that produced the maximum increase of oxylipin production (Fig. 12G). Finally, the fungal protein amended to the growth medium of tomato seedling at $0.15,2.5$, and 5.0 $\mu \mathrm{M}$ enhanced expression of PR1 and PR4 but not that of PIN2encoding genes (Fig. 13). Also, in this case, the strongest response (up to a 14-fold increase) was obtained with $2.5 \mu \mathrm{M}$. Interestingly, watering of Arabidopsis with a solution of 0.1 $\mu \mathrm{M}$ doubled the level of jasmonic acid, while that of salicylic acid was not altered after 4 weeks of growth (data not shown).

Transgenic expression and targeted knock-out.

Hytlol was transgenically expressed in tomato and tobacco by using the Agrobacterium tumefaciens transient assay (ATA) and a Potato virus $X$ (PVX)-based construct. Hytlol expression in planta was confirmed by DotBlot hybridization and reversetranscriptase (RT)-PCR (data not shown), and two different tomato lines (HYTLO2 and HYTLO4) were selected for further testing. The effect of the transgenic expression of the fungal hydrophobin in planta includes i) a promoted growth associated with an epinastic deformation of the leaves in tomato
(Fig. 14A); ii) an enhanced formation and development of new roots in tomato, as seen, for instance, when cuttings of lateral stem branches or of leaves were simply dipped in water for a few days (Fig. 14B); and iii) an increased weight and develop-

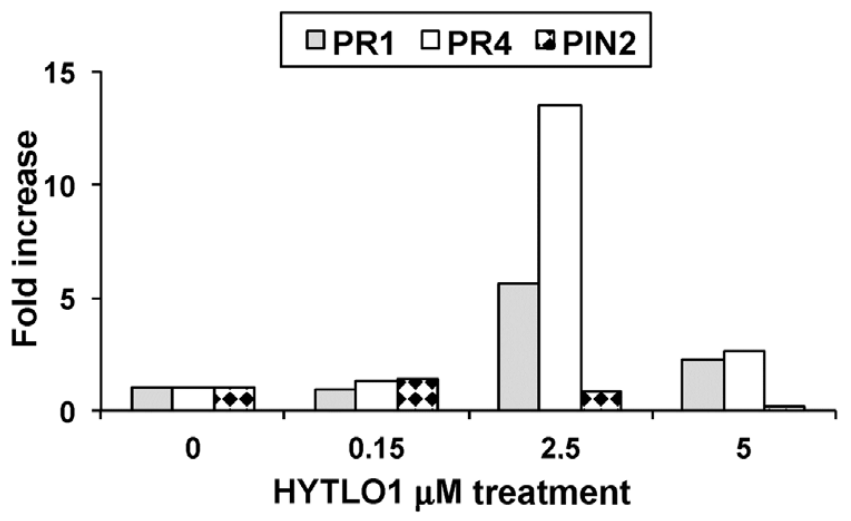

Fig. 13. Effect of HYTLO1 application on PR1, PR4, and PIN2 expression in tomato seedlings. Protein solution at the indicated concentration was applied to the growth medium and target gene expression was determined by quantitative reverse-transcriptase polymerase chain reaction $24 \mathrm{~h}$ after treatment. Expression levels are reported as fold increase relative to the untreated control. Results shown are from one representative experiment out of three.
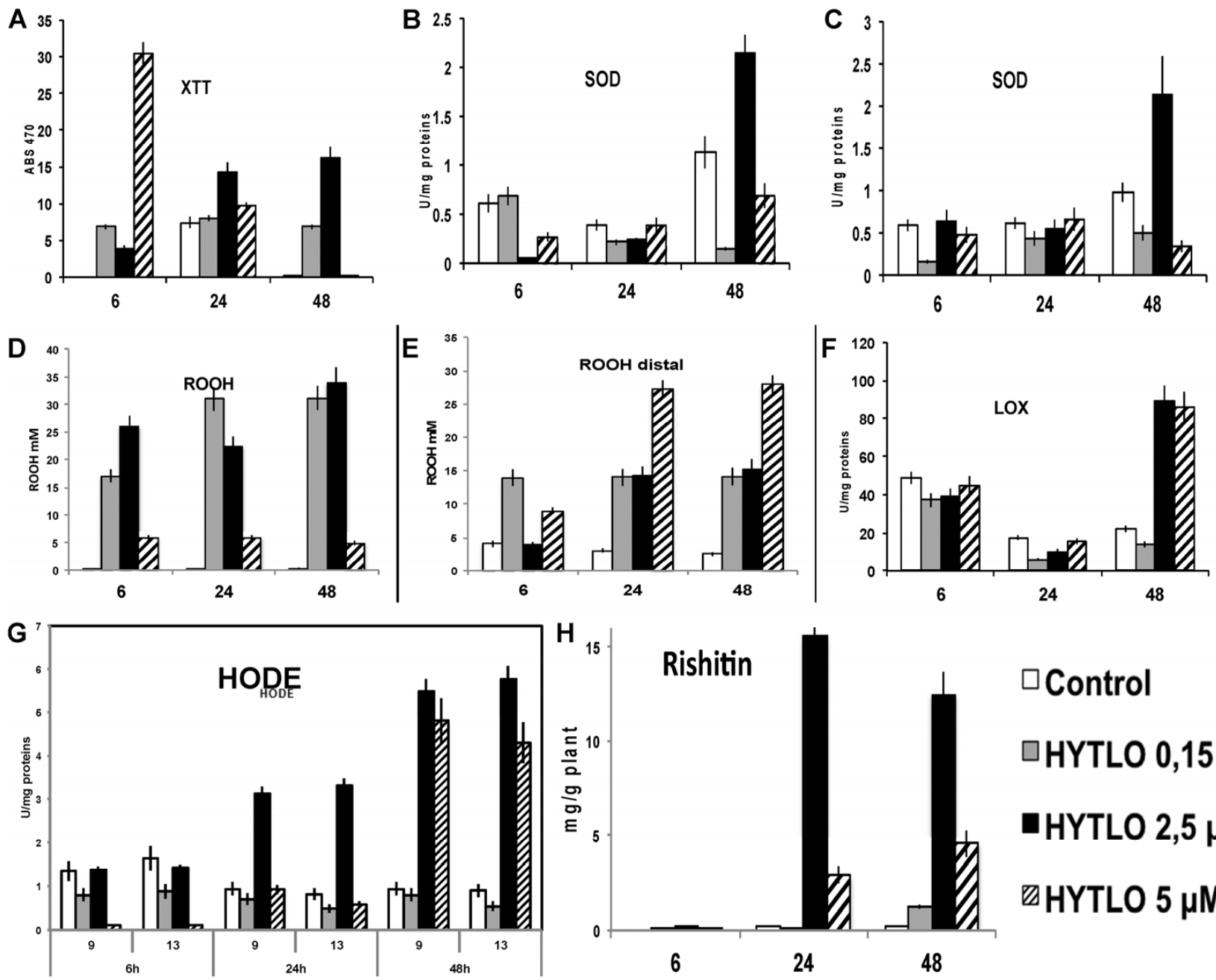

$\square$ Control

口HYTLO $0,15 \mu \mathrm{M}$

-HYTLO 2,5 $\mu \mathrm{M}$

HYTLO $5 \mu \mathrm{M}$

Fig. 12. Activation of defense-related response of tomato by a solution of purified HYTLO1. Leaves were injected with the protein (water plus the solvent as a control) and analyzed after 6, 24, and $48 \mathrm{~h}$ (x axis on the graphs) for A, accumulation of superoxide anion by using the XTT assay; stimulation of SOD activity at $\mathbf{B}, \mathrm{pH} 7.8$ and $\mathbf{C}, \mathrm{pH} 10.0$; production of peroxides (R-OOH) in $\mathbf{D}$, treated and $\mathbf{E}$, distal leaves by using the FOX1 assay; increased general $\mathbf{F}$, LOX and G, HODE (LOX 9 + LOX 13) activity; and $\mathbf{H}$, accumulation of rishitin by a thin-layer chromatography-based assay. Values are means of three replicates from two different experiments. Bars represents standard error. 
ment of tobacco leaves (Fig. 14C and D). Further, the two selected transgenic lines of tomato developed smaller necrotic areas when leaf-inoculated with $B$. cinerea (Fig. 15), as detected 1 to 3 days after the pathogen application.

Targeted gene knock-out of Hytlol was obtained in T. longibrachiatum MK1 and confirmed by RT-PCR and Northern and Southern analysis (Supplementary Fig. S2A through C). Compared with the wild type (WT), the six transformants, selected among those showing a single insertion, had a comparable growth rate on solid or liquid substrates, produced spores similar in color and shape, and did not accumulate in the culture filtrate a HYTLO1 band detectable by silver staining (data not shown). The mutants were much less mycoparasitic than the WT when tested on dual-culture plates against $R$. solani, Pythium ultimum, or B. cinerea but acted similarly to the WT against $A$. alternata (Supplementary Fig. S3). Coating of tomato seed with the selected $\Delta H y t l o l$ mutants resulted in a reduced ISR-mediated biocontrol effect, as demonstrated by following the development of necrotic lesions caused by $B$. cinerea inoculated on the leaves (Fig. 16A). In addition, the loss of Hytlol function negatively affected the MK1 ability to stimulate root development (Fig. 16B) and increase the plant fresh weight.

\section{DISCUSSION}

Hydrophobins have a recognized role in a variety of biological functions in fungi, ranging from formation of aerial structures to stimulation of the interaction with potential hosts or symbiotic partners (Sunde et al. 2008; Tagu et al. 2002). They may also affect soil structure and properties; for example, by supporting the formation of hydrophobic patches that prevent water penetration (Rillig 2005). Fungi of the Trichoderma genus have been found to produce a wide range of hydrophobins, with 42 class II of them identified from nine different species and grouped in the three clearly distinct clades HFB1/2, HFB3, and HFB4 (Kubicek et al. 2008). HYTLO1 is a class II hydrophobin, as deduced from its nucleotidic and aminoacidic sequence, and belongs to HFB1/2 clade, together with HFB2 (Hypocrea iecorina), TCK2 (T. cf. koningiopsis), HV_1a (H. virens), and TAE_3 (T. aggressivum var. europeae).

Strains of Trichoderma, especially those selected for agricultural applications, are well described as capable of interacting in a variety of ways with other microbes, plants, soil com-

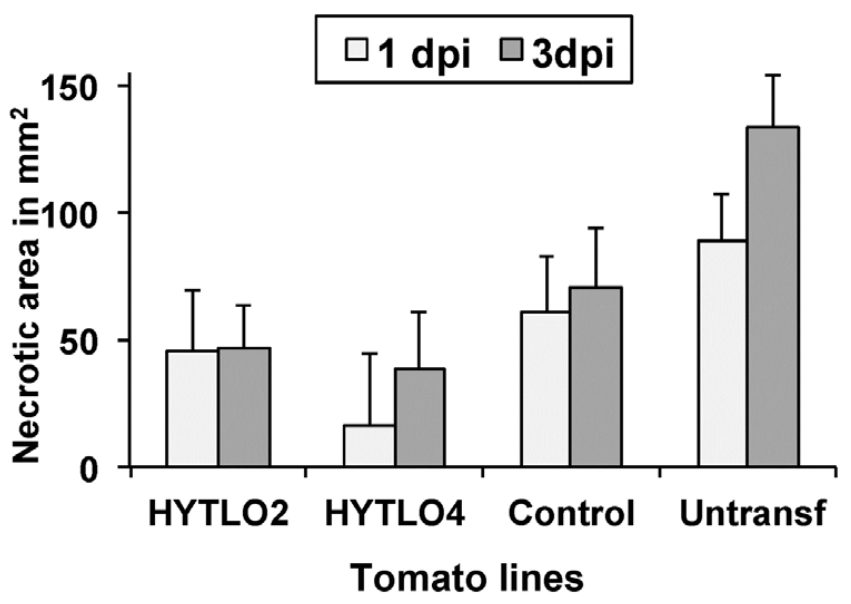

Fig. 15. Effect of tomato transgenic expression of Hytlol on Botrytis cinerea lesion development. Two transgenic lines (HYTLO2 and HYTLO4) showing different levels of expression of the transgene were tested for up to 3 days postinculation (dpi). Control $=$ empty vector transformed line. Untransf $=$ nontransformed. Bars indicated standard deviations
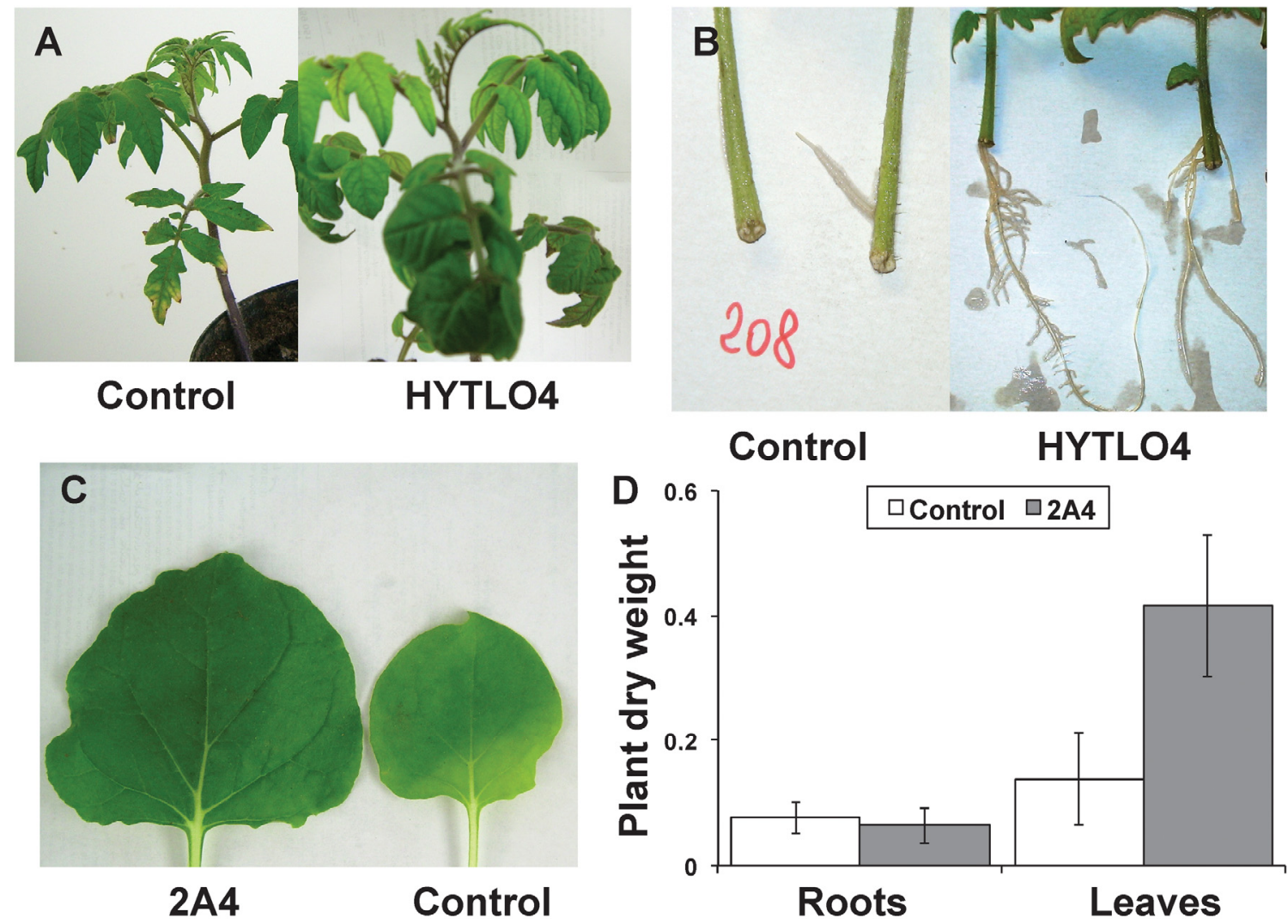

Fig. 14. Effect of transgenic expression of Hytlol on tomato and tobacco plants. A, Increased development and epinastic effect on the transformant HYTLO4; B, promotion of ex novo root formation from stem cuttings of HYTLO4 soaked in water; $\mathbf{C}$ and $\mathbf{D}$, increased leaf size in the transformant $2 \mathrm{~A} 4$. Bars indicate standard deviations. 
pounds, nematodes, and so on (Le et al. 2009; Liu et al. 2013; Maag et al. 2014). It is not uncommon to find in literature reports that describe the ability of specific strains to concurrently act as mycoparasites or direct pathogen antagonists, plant defense response inducers, as well as growth stimulators, by using multiple molecular mechanisms. Therefore, it is expected to find, in the interaction proteome or metabolome, molecules having different roles and biological properties (Vinale et al. 2012). The results presented in this article indicate that the newly found hydrophobin HYTLO1, constitutively produced and abundantly secreted in culture filtrate by T. longibrachiatum MK1, is involved in mycoparasitism, ISR activation, and plant growth stimulation.

The direct antifungal activity of HYTLO1 seems to be a peculiar characteristic of this hydrophobin produced by $T$. longibrachiatum, because similar proteins isolated, for instance, from two strains of $T$. harzianum, including the widely used T22, were not inhibitory on at least two different fungal pathogens (Fig. 4B). In fact, this property was not reported for other hydrophobic proteins isolated from $T$. virens, T. atroviride, and T. asperellum such as SM1, EPL1, and EPLT4. Coherently, we found a role for HYTLO1 in mycoparasitism based on the reduced ability of the knock-out mutants to overgrow different fungal hosts in dual-culture plate assays. Direct antifungal ac-
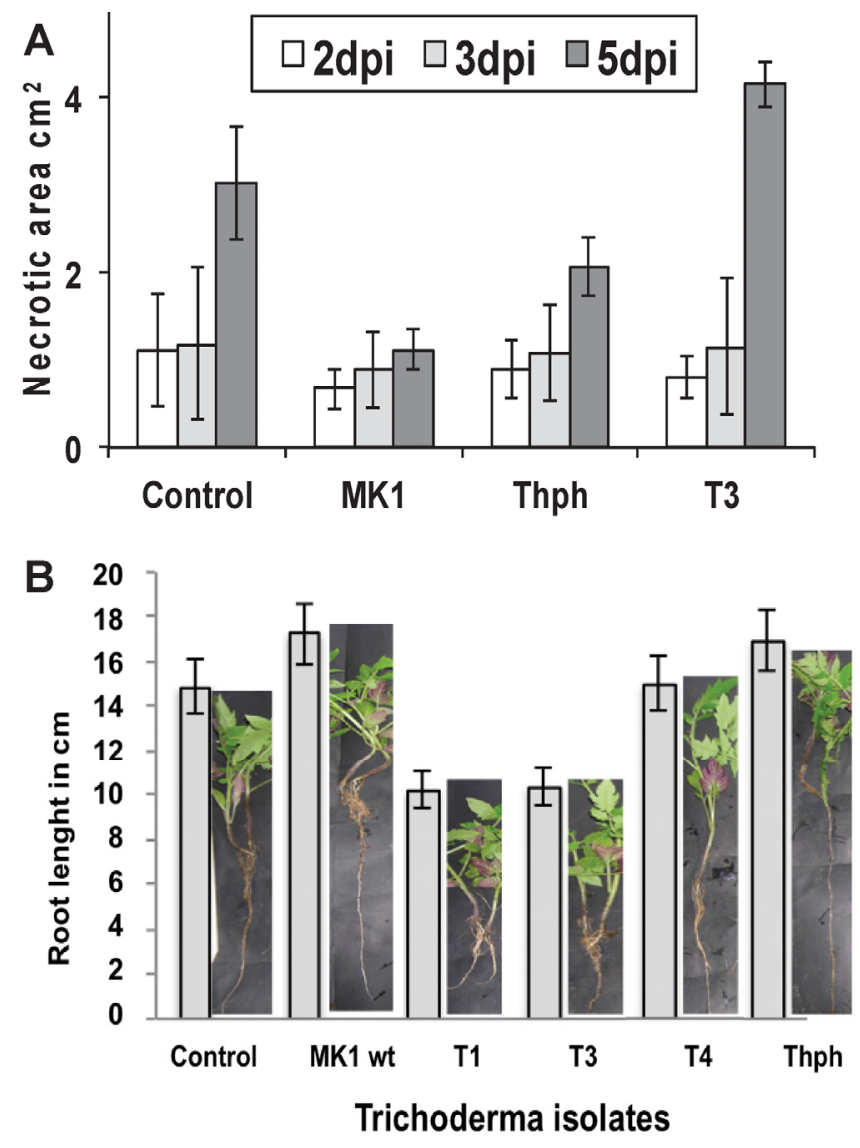

Fig. 16. Effect of targeted Hytlolknock-out on Trichoderma longibrachiatum $\mathbf{A}$, induced systemic resistance and $\mathbf{B}$, plant growth promoting ability. A, Lesion development on leaves of tomato plants challenged with Botrytis cinerea and seed-treated with water (Control), T. longibrachiatum MK1 wild type (WT), a selected $\Delta$ Hytlolmutant (T3), or an empty vector transformant (Thph), as tested for up to 5 days postinoculation (dpi). B, Root growth of tomato plants seed-treated with water, MK1 WT, three selected $\Delta$ Hytlolmutants (T1, T3, and T4), or an empty vector transformant (Thph) after 4 weeks of growth. Mutant T4 is a spontaneous hygromycin-resistant mutant that lacked a stable $h p h$ cassette insertion and deletion of Hytlo1. Bars indicated standard deviations. tivity may also have allowed the hydrophobin to inhibit the growth of $B$. cinerea when co-applied on tomato leaves (Fig. 5 ). This peculiarity may be related to the capability of $T$. longibrachiatum, including strain MK1, to grow at $37^{\circ} \mathrm{C}$ and eventually colonize a variety of living tissues (Salas et al. 2011). Indeed, the potential use of this species for biocontrol has recently received more attention by the scientific community (Sobowale et al. 2010; Yi and Chi 2011; Zhang et al. 2014).

Particularly noticeable is the effect of the purified HYTLO1 on plants, applied either by infiltration, root dipping, spraying, or transgenically. The main macroscopic response was a hormone-like promotion, as seen at very low doses, of growth and development, especially at the root level, whereas the protein was phytotoxic if applied at higher concentrations (Figs. 7, 8, and 10). The stimulatory activity was even more pronounced than that of a commercially available formulation based on naphthalene acetic acid (NAA) (Fig. 9), with a response comparable with or stronger than that obtained with the application of the living fungus (Fig. 8). Actually, the effect of either MK1 or the commercial strain T22 could be significantly enhanced by adding to the soil or spraying on the plants purified HYTLO1 at a concentration as low as $0.01 \mu \mathrm{M}$ (Figs. 8 and 9). The positive interaction was noted not only on roots but also on stem and leaves, and concerned a variety of plants (Fig. 10). Enhanced de novo root formation was clearly observed also on cuttings from tomato plants transgenically expressing the hydrophobin gene (Fig. 14). Finally, the expression of Hytlol was increased by adding cellulose or tomato tissue extracts in the fungus-growing medium (Fig. 3), whereas $\Delta$ Hytlol mutants lost some of their ability to stimulate the plant root development compared with the WT (Fig. 16). All together, these data suggest that HYTLO1 has been naturally selected because it supports the mutualistic symbiosis that MK1 is able to establish with the plant, allowing the formation of more roots while providing protection from pathogens. We are further investigating the molecular base of this mechanism, and have preliminary data suggesting that HYTLO1 reduces the level of indole-3-acetic acid while it increases that of abscisic acid in Arabidopsis (M. Nigro and M. Grant, personal communication), and stimulates hypocotyl bean curving due to an accelerated development (data not shown).

HYTLO1 was also able to act as a MAMP, by eliciting the plant defense response. For instance, tomato and bean leaves were more resistant to $B$. cinerea when the hydrophobin was applied transgenically or in a purified form (Figs. 6 and 15). This was a somehow expected effect, because it has been reported also for SM1 on cotton cotyledons challenged with the foliar pathogen Colletotrichum sp. (Djonovic et al. 2006). Several reports indicate that the proteome and metabolome of plants interacting with effective Trichoderma strains are substantially modified, including an upregulation of genes involved in defense response, ROS scavenging, stress response, isoterpenoid and ethylene biosynthesis, photosynthesis, and amino acid and carbohydrate metabolism (Marra et al. 2006; Segarra et al. 2007; Shoresh et al. 2010). In particular, colonization by T. harzianum T22 substantially enhanced the redox state of tomato, increasing the activity of SOD and peroxidase as well as that of ROS scavenging (Mastouri et al. 2012). In fact, the treatment with purified HYTLO1 stimulated tomato antioxidant defenses. The detected reaction in tomato included an increase in i) superoxide anion formation, followed by a rapid decline of the ROS level; ii) SOD activation, but not on distal leaves; iii) concentration of peroxides, as typically associated with an oxidative burst, also on distal leaves; and iv) LOX9 and LOX13 activity (Fig. 12). LOX stimulation has been reported in cucumber (Shoresh et al. 2005), Arabidopsis (Segarra et al. 2009), and tomato (Mastouri et al. 2012; Tucci et al. 2011) 
treated with living Trichoderma spp., while peroxidase was enhanced, both locally and systemically, by the application of either the microbe or the hydrophobin-like protein SM1 (Brotman et al. 2013; Djonovic et al. 2006; Segarra et al. 2007, 2009; Yedidia et al. 2003). A controlled formation of lipoperoxides due to LOX activity on polyunsaturated fatty acids such as linoleic and linolenic acid can serve as a source of secondary messengers (Vijayan et al. 1998) and defensive compounds (Hamberg 2000). These data, together with the increased accumulation of the phytoalexin rishitin (Fig. 12H) and other phenolic compounds (Fig. 11), PR1 and PR4 (Fig. 13), as well as of jasmonic acid content, clearly indicate that $T$. longibrachiatum, also by means of HYTLO1, elicits a plant defense program somehow similar to that activated by a pathogen (Bhattacharya et al. 2010; Zipfel 2008). In fact, plants treated with HYTLO1 were more resistant to a pathogen challenge, both locally and systemically (Figs. 5 and 6). Interestingly, we have recently demonstrated that the same $T$. longibrachiatum strain that secretes HYTLO1 also increases tomato attractiveness to beneficial insects (predators and parasitoids) by substantially modifying the pattern of released volatile compounds (Battaglia et al. 2013).

The data presented in this article clearly indicate that HYTLO1 or the encoding gene represents an important rhizospheric signal in plant-Trichoderma spp. interaction and could be regarded as a symbiosis-related protein. Finally, it has a significant biotechnological value, because this fungal hydrophobin can be useful for direct treatment of crops or transgenically to enhance plants or beneficial microbes.

\section{MATERIALS AND METHODS}

Fungal strains and plant species.

The HYTLO1 hydrophobin and the encoding gene were obtained from strain MK1 of T. longibrachiatum (Battaglia et al. 2013), which was isolated from tomato roots and selected for its rhizosphere competence, PGP effect, and biocontrol ability. Hydrophobins were also obtained from the commercially used strain T22 (Trianum, Koppert) and the biocontrol fungus $T$. harzianum M10 (Vinale et al. 2013). The pathogens B. cinerea, A. alternata, $P$. ultimum, and $R$. solani were obtained from the culture collection of the Department of Agriculture of the University of Naples Federico II, Italy. Mature spores or fresh mycelia, both obtained in potato dextrose agar (PDA) petri dishes, were used for the assays. T. longibrachiatum was grown in MS base medium plus $1 \%$ sucrose unless differently indicated. The plants (Arabidopsis thaliana, Capsicum annuum, Cucumis sativus, Cucurbita pepo, Nicotiana benthamiana, Solanum lycopersicum, Lotus japonicum, and Cynara cardunculus) used in this study were grown in a growth chamber at $25^{\circ} \mathrm{C}$ and $80 \%$ relative humidity $(\mathrm{RH})$ with a photoperiod of $16 \mathrm{~h}$ of light, or in vitro in agarized MS base medium amended with $1 \%$ sucrose.

\section{Hytlo1 purification and characterization.}

A T. longibrachiatum spore suspension $\left(100 \mu \mathrm{l}\right.$ of $10^{8}$ spores $/ \mathrm{ml}$ ) was used to inoculate Erlenmeyer flasks containing $100 \mathrm{ml}$ of MS plus ground tomato tissue (1\%). After 7 days at $25^{\circ} \mathrm{C}$ and $150 \mathrm{rpm}$, the culture filtrate $(\mathrm{CF})$ was separated from the biomass by filtration with Miracloth paper (Calbiochem, La Jolla, CA, U.S.A.) and subsequent centrifugation at 20,000 rpm for $20 \mathrm{~min}$. The obtained clear CF was poured into a separator funnel, vigorously shaken for $5 \mathrm{~min}$, and decanted for an additional $5 \mathrm{~min}$. The upper phase, made of stable foam, was recovered and dissolved in $70 \%$ ethanol. Protein concentration was determined fluorometrically by using the Qubit protein assay kit (Invitrogen) and samples were stored at $-20^{\circ} \mathrm{C}$ until use. For SDS polyacrylamide gel electrophoreses (PAGE), aliquots of $1 \mu \mathrm{g}$ of proteins obtained from the foam were dissolved in a $0.05 \mathrm{M}$ Tris- $\mathrm{HCl}(\mathrm{pH} \mathrm{8.8)}$ and $6 \mathrm{M}$ urea buffer and then loaded onto $16 \%$ polyacrylamide gels for SDS-PAGE, as described elsewhere (Marra et al. 2006). Sequencing of the excised protein band was performed at the CNR-ISPA, Italy. ExPASy, EMBOSS, and ClustalW were used for computational analysis and sequence alignments.

\section{Cloning and analysis of Hytlo1 gene.}

Starting from the 15 amino acids obtained by N-terminal sequencing, the cloning of the complete Hytlol cDNA was obtained by using the 5'/3' RACE kit (Roche, Basel, Switzerland), following the manufacturer's directions and the forward primer $($ Hytlo1for = GCTGTCTGCCCTACC). The obtained amplicon of about $400 \mathrm{bp}$ in size was excised from the gel and cloned in the pGEMT Easy vector (Promega Corp., Madison, WI, U.S.A.), followed by sequencing (MWG Biotech AG, Ebersberg, Germany) and BLASTX analysis. To obtain the Hytlo1gDNA the primer Hytlo1rev (= ACCTCGCCGAAGAC GACGT) was designed and used in combination with Hytlo1for.

For Southern analysis, $5 \mu \mathrm{g}$ of genomic (g)DNAs from the T. longibrachiatum WT or the transformants were overnight digested with HindIII and a standard protocol was used (Ruocco et al. 2009) Hybridization was performed at $42^{\circ} \mathrm{C}$ for $18 \mathrm{~h}$ in digoxigenin (DIG) easy Hyb buffer (Roche, Basel, Switzerland) by using the complete DIG-labeled gDNA as a probe (361 bp). For Northern analysis, 2-day-old mycelia for RNA extraction were obtained in MS $+1 \%$ celluose, chitin, tomato tissue, glucose, $R$. solani $\mathrm{CF}$, or $R$. solani cell walls. The protocol is described elsewhere (Ruocco et al. 2009), with the DIG-labeled 361-bp Hytlo1 gDNA used as the probe.

\section{Targeted disruption of Hytlo1.}

For targeted gene disruption, the following primers were used to obtain two Hytlol 5' and 3' fragments of 201 bp (MA$\mathrm{MB}$ ) and $227 \mathrm{bp}$ (MC-MD), respectively: MA (GCTGCAGAT CTACCGGCCTCTTCTCC) and MB (GGGCTTAGGCCTCA GAACACCCTGC), containing BglII and StuI restriction sites, respectively, at 5'; and MC (CAGTAATCTAGAGTTTGCTTT ACC) and MD (TTTTTTAAGCTTCTTTTCTCATATG), containing $X b a \mathrm{I}$ and HindIII restriction sites, respectively, at $5^{\prime}$. The pAN7-1 (Punt et al. 1987) was digested with XbaI and $H$ indIII to accommodate the MC-MD fragment and with $B g l I I$ and $S t u \mathrm{I}$ to insert the MA-MB fragment. The resulting construct, containing Hytlol interrupted by the $h p h$ gene, was used with a standard protoplast transformation to obtain $\Delta H y t l o l$ mutants of T. longibrachiatum MK1 (Ruocco et al. 2009). Progenies were selected on PDA + hygromycin at $100 \mathrm{ppm}$, single spored, and PCR analyzed by using the Hytlolfor and Hytlo1rev primers, as well as by Southern and Northern analysis as described above.

\section{Direct antifungal activity.}

T. longibrachiatum and pathogen spores were incubated in potato dextrose broth (PDB) (Difco) in flat-bottom tissue culture plates at $25^{\circ} \mathrm{C}$ (Lorito et al. 1996) in the presence of HYTLO1 at the indicated concentrations. Assay mixtures contained $20 \mu \mathrm{l}$ of a conidial suspension $\left(10^{5}\right.$ to $\left.10^{6} \mathrm{conidia} / \mathrm{ml}\right)$ of the tested fungi (B. cinerea, Alternaria alternata, or T. longibrachiatum), $70 \mu \mathrm{l}$ of $1 \times$ PDB, and $10 \mu \mathrm{l}$ of HYTLO1 water solution. Controls contained water + ethanol (HYTLO1 solvent) at the appropriate concentration $(<0.5 \%)$. Spore germination was evaluated optically and microscopically after $24 \mathrm{~h}$ (Fig. 4A) and $72 \mathrm{~h}$ (Fig. 4B). Dual-plate inhibition assays of $\Delta H y$ tlol mutants against $R$. solani, B. cinerea, A. alternata, and P. ultimum were performed as described by Ruocco and associates (2009). 


\section{Plant protection assays.}

For all of the tests, plant seed were sterilized in $2 \%$ sodium hypochlorite for $20 \mathrm{~min}$ and thoroughly washed in sterile distilled water before seeding in pots (two plants each) containing 1 liter of soil. Co-application experiments (Fig. 5) were performed by adding $10 \mu \mathrm{l}$ of a solution of purified HYTLO1 at different concentration and $10 \mu \mathrm{l}$ of solvent solution $(0.5 \%$ ethanol) as the control. A B. cinerea spore suspension (10 $\mu \mathrm{l}$ at $10^{6} \mathrm{ml}^{-1}$ ) was applied $2 \mathrm{~h}$ later at the same point, and plants were enveloped in transparent plastic bags and incubated in a growth chamber at $18^{\circ} \mathrm{C}$ with a photoperiod of $16 \mathrm{~h}$ of light. Necrotic lesions area was determined 24, 48, and 72 hpi. Induced resistance experiments (Fig. 6) were performed by i) determining the development of symptoms in leaves distant from those injected with $10 \mu \mathrm{l}$ of the HYTLO1 solution (Fig. 6A) or ii) spraying with the HYTLO1 solution the basal leaves of 5-week-old plants, of which the upper part was enveloped in a plastic bag, followed by $B$. cinerea infection (see above) after $24 \mathrm{~h}$ on the nontreated leaves. When a Trichoderma treatment was present (WT or mutants), the protocol described by Tucci and associates (2011) was used.

\section{PGP assays.}

In vitro tests were performed by germinating plants on agarized MS $+1 \%$ sucrose containing HYTLO1 at different concentrations or water $(<0.5 \%$ ethanol) as a control, or by leaving cuttings for 15 days at $25^{\circ} \mathrm{C}$ and $80 \% \mathrm{RH}$ in the indicated HYTLO1 solution. For in vivo tests, plants were treated with Trichoderma spores or HYTLO1 or the commercial (NAA) hormone formulation Germon-E (L. Gobbis.r.l., Genova, Italy) by soaking (Fig. 9) the plantlets or soaking the seed followed by watering or spraying (Fig. 8). In the latter case, plants were irrigated weekly with $50 \mathrm{ml}$ of an MK1 $10^{6} \mathrm{ml}^{-1}$ spore suspension or sprayed with $20 \mathrm{ml}$ of a solution containing HYTLO1 at $0.072 \mu \mathrm{g} / \mathrm{ml}(0.01 \mu \mathrm{M})$ once per week for 1 month. For comparison experiments shown in Figure 9, roots were detached from 2-week-old tomato plantlets which were then soaked for $5 \mathrm{~min}$ in water (control) or in a suspension of T. harzianum T22 spore $\left(10^{7}\right.$ spores per $\left.\mathrm{ml}\right)$, Germon-E (at the dose indicated by the manufacturer), HYTLO1 at $0.01 \mu \mathrm{M}$, or Germon-E plus HYTLO1 at the same concentrations as the compounds applied alone. $\Delta$ Hytlol mutants were tested by using the seed coating protocol described by Tucci and associates (2011).

\section{Plant molecular response.}

Macroscopic effect of HYTLO1 leaf injection was determined by using the protocol described above. Molecular response of tomato plants was determined on lyophilized tissues (10 mg) collected 6 to $48 \mathrm{hpi}$ and homogenized in liquid nitrogen. Anion superoxide (Fig. 12A) was detected by measuring the reduction of 2,3-bis (2-methoxy-4-nitro-5-sulfophenyl)-5[(phenylamino) carbonyl]-2H-tetrazolium hydroxide (XTT) to formazan (Sutherland and Learmonth 1997), with XTT levels expressed as mean absorbance values per milligram of tissue \pm standard errors of the means. Total hydroperoxides (R-OOH) (Fig. 12D and E) were spectrophotometrically analyzed at 560 $\mathrm{nm}$ by monitoring the oxidation of xylenol orange with the modification described by Banerjee and associates (2003). SOD at pH 7.8 and 10.0 (EC 1.15.1.1) and LOX enzyme (EC 1.13.11.12) activities (Fig. 12B, C, and F) were determined as described elsewhere (Reverberi et al. 2006). Hydroperoxyoctadecadienoic acid (9- and 13-HPODE) content was measured by high-performance liquid chromatography mass spectrometry using the protocol described by Reverberi and associates (2006). For determination of rishitin content, $50 \mathrm{mg}$ of tissue was extracted with methylene chloride $(2 \mathrm{ml})$ in the presence of $100 \mu \mathrm{g}$ of BHT. Tubes were left in a fume hood for 15 or 20 min and occasionally shaken, while the extracts were filtered (Whatmann $3 \mathrm{MM}$ ) and dried under nitrogen flow. Rishitin was quantified by gas chromatography mass spectrometry as described by Fanelli and associates (1992). Quantitative RTPCR analysis of the genes encoding for PR1, PR4, and PIN was performed in tomato by using the protocol described by Tucci and associates (2011). All the PCRs displayed efficiencies close to $100 \%$, which allowed normalization and realistic comparisons.

\section{Hytlo1 transgenic expression in plant.}

In order to make the ATA construct, the full-length HytlolcDNA was amplified by PCR with primers Hytlo1CLAfor $\left(5^{\prime}\right.$ ATCGATTATGGCTGTCTGCCCTACCGGC-3') and Hytlo1SALrev (5'-GTCGACTAACTGGGTGCCGATGGGC-3'), which introduced a $C l a \mathrm{I}$ and a SalI restriction site at the $5^{\prime}$ and $3^{\prime}$ end, respectively. The obtained amplicon was subcloned into pGEM-T Easy vector, and ligated as a ClaI-SalI fragment in the pGR106 vector (Takken et al. 2000). The construct containing the insert in sense orientation was designated PVX:: Hytlol. The obtained binary vector and the pGR208 vector (Rairdan et al. 2008) containing the green fluorescent protein cDNA ligated in the pGR106 vector were transferred to Agrobacterium tumefaciens GV3101. N. benthamiana and S. lycopersici seedlings at fourth true-leaf stage were used for $A$. tumefaciens inoculation by wounding the leaves with a toothpick previously streaked over an agar plate containing the appropriate $A$. tumefaciens clone (Horsch et al. 1985). Each PVX construct combination was assayed on three different leaves of at least 10 different plants, and each experiment was repeated at least twice. Plants were challenged with $B$. cinerea as described above 2 weeks after $A$. tumefaciens transformation and appearance of necrotic areas was assessed 2 to 3 days after inoculation. PGP effect was determined as described above.

\section{Statistical analysis.}

Normally, mean values from at least three different experiments with at least five replicates per treatment were used for the graphs, with either standard deviation or error or the Tukey's and Dunn's tests at the significance level $P<0.001$ calculated.

\section{ACKNOWLEDGMENTS}

We thank P. Cascone and V. Matteoli for the help with the statistical analysis and the in vivo assays. This research has been supported by the Italian Ministry of Economy and Finance to the National Research Council for the project Innovazione e Sviluppo del MezzogiornoConoscenze Integrate per Sostenibilità ed Innovazione del Made in Italy Agroalimentare-Legge number 191/2009; The European Union Seventh Framework Programme (FP7/ 2007-2013) PURE under the grant agreement number 265865; GenoPOM-pro PON02_00395_3082360 and Linfa PON03PE_00026_1, funded by the Italian Ministry of Education, University and Research (MIUR), Programma Operativo Nazionale Ricerca \& Competitività (PON R\&C) 2007-2013. Strategie di Recupero e valorizzazione del Processo Produttivo delle Olive da Tavola funded by Calabria Region, APQ. Caratterizzazione, Sviluppo e Produzione di Oli Extra Vergini di Oliva e Valorizzazione del Recupero dei Sottoprodotti di Produzione; and Miglioramento delle Produzioni olearie e Recupero delle acque di Vegetazione, funded by Calabria Region, Piano di Sviluppo Rurale Misura 124. Progetto Integrato Limone (PIL) funded by Campania Region, GRAPE AND HEALTH WINE funded by Ministry of Economic Development-PII Made in Italy. Sicurezza e Innovazione Tecnologica Utile alla salvaguardia e valorizzazione dei prodotti tipici di oRigine Animale-Sicura, funded by the MIUR, PON R\&C 2007-2013 Grandi Progetti Strategici PON R\&C 2007-2013. Sicurezza, sostenibilità e competitività nelle produzioni agroalimentari della Campania CUP B25B09000080007. 


\section{LITERATURE CITED}

Acioli-Santos, B., Sebastiana, M., Pessoa, F., Sousa, L., Figueiredo, A., Fortes, A. M., Balde, A., Maia, L. C., and Pais, M. S. 2008. Fungal transcript pattern during the preinfection stage $(12 \mathrm{~h})$ of ectomycorrhiza formed between Pisolithus tinctorius and Castanea sativa roots, identified using cDNA microarrays. Curr. Microbiol. 57:620-625.

Alizadeh, H., Behboudi, K., Ahmadzadeh, M., Javan-Nikkhah, M., Zamioudis, C., Pieterse, C. M. J., and Bakker, P. A. H. M. 2013. Induced systemic resistance in cucumber and Arabidopsis thaliana by the combination of Trichoderma harzianum Tr6 and Pseudomonas sp. Ps14. Biol. Control 65:14-23.

Altomare, C., Norvell, W. A., Bjorkman, T., and Harman, G. E. 1999. Solubilization of phosphates and micronutrients by the plant-growthpromoting and biocontrol fungus Trichoderma harzianum Rifai 129522. Appl. Environ. Microbiol. 65:2926-2933.

Atanasova, L., Le Crom, S., Gruber, S., Coulpier, F., Seidl-Seiboth, V., Kubicek, C. P., and Druzhinina, I. S. 2013. Comparative transcriptomics reveals different strategies of Trichoderma mycoparasitism. BMC Genomics 14:121.

Avni, A., Bailey, B. A., Mattoo, A. K., and Anderson, J. D. 1994. Induction of ethylene biosynthesis in Nicotiana tabacum by a Trichoderma viride xylanase is correlated to the accumulation of 1-aminocyclopropane-1carboxylic acid (ACC) synthase and ACC oxidase transcripts. Plant Physiol. 106:1049-1055.

Baccelli, I., Luti, S., Bernardi, R., Scala, A., and Pazzagli, L. 2014. Cerato-platanin shows expansin-like activity on cellulosic materials. Appl. Microbiol. Biot. 98:175-184.

Banerjee, D., Madhusoodanan, U. K., Sharanabasappa, M., Ghosh, S., and Jacob, J. 2003. Measurement of plasma hydroperoxide concentration by FOX-1 assay in conjunction with triphenylphosphine. Clin. Chim. Acta 337:147-152.

Battaglia, D., Bossi, S., Cascone, P., Digilio, M. C., Prieto, J. D., Fanti, P., Guerrieri, E., Iodice, L., Lingua, G., Lorito, M., Maffei, M. E., Massa, N., Ruocco, M., Sasso, R., and Trotta, V. 2013. Tomato below groundabove ground interactions: Trichoderma longibrachiatum affects the performance of Macrosiphum euphorbiae and its natural antagonists. Mol. Plant-Microbe Interact. 26:1249-1256.

Bhattacharya, A., Sood, P., and Citovsky, V. 2010. The roles of plant phenolics in defence and communication during Agrobacterium and Rhizobium infection. Mol. Plant Pathol. 11:705-719.

Brotman, Y., Briff, E., Viterbo, A., and Chet, I. 2008. Role of swollenin, an expansin-like protein from Trichoderma, in plant root colonization. Plant Physiol. 147:779-789.

Brotman, Y., Lisec, J., Meret, M., Chet, I., Willmitzer, L., and Viterbo, A. 2012. Transcript and metabolite analysis of the Trichoderma-induced systemic resistance response to Pseudomonas syringae in Arabidopsis thaliana. Microbiology 158:139-146.

Brotman, Y., Landau, U., Cuadros-Inostroza, A., Takayuki, T., Fernie, A R., Chet, I., Viterbo, A., and Willmitzer, L. 2013. Trichoderma-plant root colonization: Escaping early plant defense responses and activation of the antioxidant machinery for saline stress tolerance. PLoS Pathog. 9:e1003221

Caporale, A. G., Sommella, A., Lorito, M., Lombardi, N., Azam, S. M. G. G., Pigna, M., and Ruocco, M. 2014. Trichoderma spp. alleviate phytotoxicity in lettuce plants (Lactuca sativa L.) irrigated with arsenic-contaminated water. J. Plant Physiol. 171:1378-1384.

Collen, A., Saloheimo, M., Bailey, M., Penttila, M., and Pakula, T. M. 2005. Protein production and induction of the unfolded protein response in Trichoderma reesei strain rut-c30 and its transformant expressing endoglucanase I with a hydrophobic tag. Biotechnol. Bioeng. 89:335344.

Conrath, U., Beckers, G. J. M., Flors, V., Garcia-Agustin, P., Jakab, G., Mauch, F., Newman, M. A., Pieterse, C. M. J., Poinssot, B., Pozo, M. J., Pugin, A., Schaffrath, U., Ton, J., Wendehenne, D., Zimmerli, L., and Mauch-Mani, B. 2006. Priming: Getting ready for battle. Mol. PlantMicrobe Interact. 19:1062-1071.

Djonovic, S., Pozo, M. J., Dangott, L. J., Howell, C. R., and Kenerley, C. M. 2006. Sm1, a proteinaceous elicitor secreted by the biocontrol fungus Trichoderma virens induces plant defense responses and systemic resistance. Mol. Plant-Microbe Interact. 19:838-853.

Druzhinina, I. S., Seidl-Seiboth, V., Herrera-Estrella, A., Horwitz, B. A., Kenerley, C. M., Monte, E., Mukherjee, P. K., Zeilinger, S., Grigoriev, I. V., and Kubicek, C. P. 2011. Trichoderma: The genomics of opportunistic success. Nat. Rev. Microbiol. 9:749-759.

Fanelli, C., Castoria, R., Fabbri, A. A., and Passi, S. 1992. Novel study on the elicitation of hypersensitive response by polyunsaturated fatty acids in potato tuber. Nat. Toxins 1:136-146.

Furman-Matarasso, N., Cohen, E., Du, Q. S., Chejanovsky, N., Hanania, U., and Avni, A. 1999. A point mutation in the ethylene-inducing xy- lanase elicitor inhibits the beta-1-4-endoxylanase activity but not the elicitation activity. Plant Physiol. 121:345-351.

Hamberg, M. 2000. New cyclopentenone fatty acids formed from linoleic and linolenic acids in potato. Lipids 35:353-363.

Hanson, L.E., and Howell, C. R. 2004. Elicitors of plant defense responses from biocontrol strains of Trichoderma virens. Phytopathology 94:171176.

Harman, G. E., Howell, C. R., Viterbo, A., Chet, I., and Lorito, M. 2004. Trichoderma species-Opportunistic, avirulent plant symbionts. Nat. Rev. Microbiol. 2:43-56.

Hermosa, R., Viterbo, A., Chet, I., and Monte, E. 2012. Plant-beneficial effects of Trichoderma and of its genes. Microbiology 158:17-25.

Horsch, R. B., Fry, J. E., Hoffmann, N. L., Eichholtz, D., Rogers, S. G. and Fraley, R. T. 1985. A simple and general-method for transferring genes into plants. Science 227:1229-1231.

Kubicek, C. P., Baker, S., Gamauf, C., Kenerley, C. M., and Druzhinina, I. S. 2008. Purifying selection and birth-and-death evolution in the class II hydrophobin gene families of the ascomycete Trichoderma/Hypocrea. BMC Evol. Biol. 8:4.

Le, H., Padgham, J., and Sikora, R. 2009. Biological control of the rice root-knot nematode Meloidogyne graminicola on rice, using endophytic and rhizosphere fungi. Int. J. Pest Manage. 55:31-36.

Linder, M. B., Szilvay, G. R., Nakari-Setala, T., and Penttila, M. E. 2005. Hydrophobins: The protein-amphiphiles of filamentous fungi. FEMS (Fed. Eur. Microbiol. Soc.) Microbiol. Rev. 29:877-896.

Liu, T., Dong, D., Liu, W. C., Lu, C. G., Zhang, T. T., and Qiu, J. Y. 2013. Evaluation of Trichoderma viride for antagonistic activity against rootknot nematode Meloidogyne incognita. Phytopathology 103:83-83.

Lorito, M., and Woo, S. 2014. Trichoderma: A multi-purpose tool for integrated pest management. In: Principles of Plant-Microbe Interactions. B. J. J Lugtenberg, ed. Springer.

Lorito, M., Woo, S. L., D’Ambrosio, M., Harman, G. E., Hayes, C. K., Kubicek, C. P., and Scala, F. 1996. Synergistic interaction between cell wall degrading enzymes and membrane affecting compounds. Mol. Plant-Microbe Interact. 9:206-213.

Lorito, M., Woo, S. L., Harman, G. E., and Monte, E. 2010. Translational research on Trichoderma: From 'Omics to the field. Annu. Rev. Phytopathol. 48:395-417.

Maag, D., Kandula, D. R. W., Muller, C., Mendoza-Mendoza, A., Wratten, S. D., Stewart, A., and Rostas, M. 2014. Trichoderma atroviride LU132 promotes plant growth but not induced systemic resistance to Plutella xylostella in oilseed rape. Biocontrol 59:241-252.

Malmierca, M. G., Cardoza, R. E., Alexander, N. J., McCormick, S. P., Hermosa, R., Monte, E., and Gutierrez, S. 2012. Involvement of Trichoderma trichothecenes in the biocontrol activity and induction of plant defense-related genes. Appl. Environ. Microbiol. 78:4856-4868.

Marra, R., Ambrosino, P., Carbone, V., Vinale, F., Woo, S. L., Ruocco, M., Ciliento, R., Lanzuise, S., Ferraioli, S., Soriente, I., Gigante, S., Turra, D., Fogliano, V., Scala, F., and Lorito, M. 2006. Study of the three-way interaction between Trichoderma atroviride, plant and fungal pathogens by using a proteomic approach. Curr. Genet. 50:307-321.

Martellini, F., Faoro, F., Carresi, L., Pantera, B., Baccelli, I., Maffi, D., Tiribilli, B., Sbrana, F., Luti, S., Comparini, C., Bernardi, R., Cappugi, G., Scala, A., and Pazzagli, L. 2013. Cerato-populin and cerato-platanin, two non-catalytic proteins from phytopathogenic fungi, interact with hydrophobic inanimate surfaces and leaves. Mol. Biotechnol. 55:27-42.

Martinez, C., Blanc, F., Le Claire, E., Besnard, O., Nicole, M., and Baccou, J. C. 2001. Salicylic acid and ethylene pathways are differentially activated in melon cotyledons by active or heat-denatured cellulase from Trichoderma longibrachiatum. Plant Physiol. 127:334-344.

Martinez-Medina, A., Fernandez, I., Sanchez-Guzman, M. J., Jung, S. C. Pascual, J. A., and Pozo, M. J. 2013. Deciphering the hormonal signaling network behind the systemic resistance induced by Trichoderma harzianum in tomato. Front. Plant Sci. 4:206.

Mastouri, F., Bjorkman, T., and Harman, G. E. 2012. Trichoderma harzianum enhances antioxidant defense of tomato seedlings and resistance to water deficit. Mol. Plant-Microbe Interact. 25:1264-1271.

Montillet, J. L., Cacas, J. L., Garnier, L., Montane, M. H., Douki, T., Bessoule, J. J., Polkowska-Kowalczyk, L., Maciejewska, U., Agnel, J. P., Vial, A., and Triantaphylides, C. 2004. The upstream oxylipin profile of Arabidopsis thaliana: A tool to scan for oxidative stresses. Plant J. 40:439-451.

Perazzolli, M., Roatti, B., Bozza, E., and Pertot, I. 2011. Trichoderma harzianum T39 induces resistance against downy mildew by priming for defense without costs for grapevine. Biol. Control 58:74-82.

Punt, P. J., Oliver, R. P., Dingemanse, M. A., Pouwels, P. H., and Vandenhondel, C. A. M. J. J. 1987. Transformation of Aspergillus based on the hygromycin-B resistance marker from Escherichia coli. Gene $56: 117-124$. 
Qi, W. Z., and Zhao, L. 2013. Study of the siderophore-producing Trichoderma asperellum $\mathrm{Q} 1$ on cucumber growth promotion under salt stress. J. Basic Microbiol. 53:355-364.

Rairdan, G. J., Collier, S. M., Sacco, M. A., Baldwin, T. T., Boettrich, T., and Moffett, P. 2008. The coiled-coil and nucleotide binding domains of the potato $\mathrm{Rx}$ disease resistance protein function in pathogen recognition and signaling. Plant Cell 20:739-751.

Reverberi, M., Zjalic, S., Ricelli, A., Fabbri, A. A., and Fanelli, C. 2006. Oxidant/antioxidant balance in Aspergillus parasiticus affects aflatoxin biosynthesis. Mycotoxin Res. 22:39-47.

Rillig, M. C. 2005. A connection between fungal hydrophobins and soil water repellency? Pedobiologia 49:395-399.

Rotblat, B., Enshell-Seijffers, D., Gershoni, J. M., Schuster, S., and Avni, A. 2002. Identification of an essential component of the elicitation active site of the EIX protein elicitor. Plant J. 32:1049-1055.

Ruocco, M., Lanzuise, S., Vinale, F., Marra, R., Turra, D., Woo, S. L., and Lorito, M. 2009. Identification of a new biocontrol gene in Trichoderma atroviride: The role of an $\mathrm{ABC}$ transporter membrane pump in the interaction with different plant-pathogenic fungi. Mol. Plant-Microbe Interact. 22:291-301.

Salas, C. F. S., Joshi, A. Y., Dhiman, N., Banerjee, R., Huskins, W. C., Wengenack, N. L., and Henry, N. K. 2011. Fatal post-operative Trichoderma longibrachiatum mediastinitis and peritonitis in a paediatric patient with complex congenital cardiac disease on peritoneal dialysis. J. Med. Microbiol. 60:1869-1871.

Samolski, I., Rincon, A. M., Pinzon, L. M., Viterbo, A., and Monte, E. 2012. The qid74 gene from Trichoderma harzianum has a role in root architecture and plant biofertilization. Microbiology 158:129-138.

Segarra, G., Casanova, E., Bellido, D., Odena, M. A., Oliveira, E., and Trillas, I. 2007. Proteome, salicylic acid, and jasmonic acid changes in cucumber plants inoculated with Trichoderma asperellum strain T34. Proteomics 7:3943-3952.

Segarra, G., Van der Ent, S., Trillas, I., and Pieterse, C. M. J. 2009. MYB72, a node of convergence in induced systemic resistance triggered by a fungal and a bacterial beneficial microbe. Plant Biol. 11:90-96.

Seidl, V., Druzhinina, I. S., and Kubicek, C. P. 2006a. A screening system for carbon sources enhancing beta-N-acetylglucosaminidase formation in Hypocrea atroviridis (Trichoderma atroviride). Microbiology 152:2003-2012.

Seidl, V., Marchetti, M., Schandl, R., Allmaier, G., and Kubicek, C. P. 2006b. Epl1, the major secreted protein of Hypocrea atroviridis on glucose, is a member of a strongly conserved protein family comprising plant defense response elicitors. FEBS (Fed. Eur. Biochem. Soc.) J. 273:4346-4359.

Shoresh, M., Yedidia, I., and Chet, I. 2005. Involvement of jasmonic acid/ethylene signaling pathway in the systemic resistance induced in cucumber by Trichoderma asperellum T203. Phytopathology 95:7684.

Shoresh, M., Harman, G. E., and Mastouri, F. 2010. Induced systemic resistance and plant responses to fungal biocontrol agents. Annu. Rev. Phytopathol. 48:21-43.

Sobowale, A. A., Odeyingbo, O. A., Egberongbe, H. O., Feyisola, R. T., Ayinde, O. A., and Adesemowo, A. 2010. Growth inhibition (in vitro) of Colletotrichum gloeosporioides isolated from cassava (Manihot esculenta) using Trichoderma longibrachiatum. Afr. J. Microbiol. Res. 4:2196-2201

Sunde, M., Kwan, A. H. Y., Templeton, M. D., Beever, R. E., and Mackay, J. P. 2008. Structural analysis of hydrophobins. Micron 39:773-784.

Sutherland, M. W., and Learmonth, B. A. 1997. The tetrazolium dyes MTS and XTT provide new quantitative assays for superoxide and superoxide dismutase. Free Radic. Res. 27:283-289.

Tagu, D., and Martin, F. 1996. Molecular analysis of cell wall proteins expressed during the early steps of ectomycorrhiza development. New Phytol. 133:73-85.

Tagu, D., Lapeyrie, F., and Martin, F. 2002. The ectomycorrhizal symbiosis: Genetics and development. Plant Soil 244:97-105.

Takken, F. L. W., Luderer, R., Gabriels, S. H. E. J., Westerink, N., Lu, R., de Wit, P. J. G. M., and Joosten, M. H. A. J. 2000. A functional cloning strategy, based on a binary PVX-expression vector, to isolate HR-inducing cDNAs of plant pathogens. Plant J. 24:275-283.

Tucci, M., Ruocco, M., De Masi, L., De Palma, M., and Lorito, M. 2011. The beneficial effect of Trichoderma spp. on tomato is modulated by the plant genotype. Mol. Plant Pathol. 12:341-354.

van den Burg, H. A., Westerink, N., Francoijs, K. J., Roth, R., Woestenenk,
E., Boeren, S., de Wit, P. J. G. M., Joosten, M. H. A. J., and Vervoort, J. 2003. Natural disulfide bond-disrupted mutants of AVR4 of the tomato pathogen Cladosporium fulvum are sensitive to proteolysis, circumvent Cf-4-mediated resistance, but retain their chitin binding ability. J. Biol. Chem. 278:27340-27346.

van den Burg, H. A., Harrison, S. J., Joosten, M. H. A. J., Vervoort, J., and de Wit, P. J. G. M. 2006. Cladosporium fulvum Avr4 protects fungal cell walls against hydrolysis by plant chitinases accumulating during infection. Mol. Plant-Microbe Interact. 19:1420-1430.

Vargas, W. A., Djonovic, S., Sukno, S. A., and Kenerley, C. M. 2008. Dimerization controls the activity of fungal elicitors that trigger systemic resistance in plants. J. Biol. Chem. 283:19804-19815.

Velazquez-Robledo, R., Contreras-Cornejo, H. A., Macias-Rodriguez, L., Hernandez-Morales, A., Aguirre, J., Casas-Flores, S., Lopez-Bucio, J., and Herrera-Estrella, A. 2011. Role of the 4-phosphopantetheinyl transferase of Trichoderma virens in secondary metabolism and induction of plant defense responses. Mol. Plant-Microbe Interact. 24:1459-1471.

Vijayan, P., Shockey, J., Levesque, C. A., Cook, R. J., and Browse, J. 1998. A role for jasmonate in pathogen defense of Arabidopsis. Proc. Natl. Acad. Sci. U.S.A. 95:7209-7214.

Vinale, F., Sivasithamparam, K., Ghisalberti, E. L., Marra, R., Woo, S. L., and Lorito, M. 2008. Trichoderma-plant-pathogen interactions. Soil Biol. Biochem. 40:1-10.

Vinale, F., Flematti, G., Sivasithamparam, K., Lorito, M., Marra, R., Skelton, B. W., and Ghisalberti, E. L. 2009. Harzianic acid, an antifungal and plant growth promoting metabolite from Trichoderma harzianum. J. Nat. Prod. 72:2032-2035.

Vinale, F., Sivasithamparam, K., Ghisalberti, E. L., Ruocco, M., Woo, S., and Lorito, M. 2012. Trichoderma secondary metabolites that affect plant metabolism. Nat. Prod. Commun. 7:1545-1550.

Vinale, F., Nigro, M., Sivasithamparam, K., Flematti, G., Ghisalberti, E. L., Ruocco, M., Varlese, R., Marra, R., Lanzuise, S., Eid, A., Woo, S L., and Lorito, M. 2013. Harzianic acid: A novel siderophore from Trichoderma harzianum. FEMS (Fed. Eur. Microbiol. Soc.) Microbiol. Lett. 347:123-129.

Vos, C., De Cremer, K., Cammue, B., and De Coninck, B. 2014. The toolbox of Trichoderma spp. in biocontrol of Botrytis cinerea disease. Mol. Plant Pathol. doi:10.1111/mpp.12189

Wang, Y., Song, J. Z., Wu, Y. J., Odeph, M., Liu, Z. H., Howlett, B. J., Wang, S., Yang, P., Yao, L., Zhao, L., and Yang, Q. 2013a. Eplt4 proteinaceous elicitor produced in Pichia pastoris has a protective effect against Cercosporidium sofinum infections of soybean leaves. Appl. Biochem. Biotechnol. 169:722-737.

Wang, Y. W., Bouillon, C., Cox, A., Dickinson, E., Durga, K., Murray, B. $\mathrm{S}$., and $\mathrm{Xu}, \mathrm{R} .2013 \mathrm{~b}$. Interfacial study of class II hydrophobin and its mixtures with milk proteins: Relationship to bubble stability. J. Agric. Food Chem. 61:1554-1562.

Wessels, J. G. H. 1999. Fungi in their own right. Fungal Genet. Biol. 27:134-145.

Whiteford, J. R., and Spanu, P. D. 2002. Hydrophobins and the interactions between fungi and plants. Mol. Plant Pathol. 3:391-400.

Wosten, H. A. B. 2001. Hydrophobins: Multipurpose proteins. Annu. Rev. Microbiol. 55:625-646.

Yedidia, I., Shoresh, M., Kerem, Z., Benhamou, N., Kapulnik, Y., and Chet, I. 2003. Concomitant induction of systemic resistance to Pseudomonas spingae pv. lachrymans in cucumber by Trichoderma asperellum (T-203) and accumulation of phytoalexins. Appl. Environ. Microbiol. 69:7343-7353

Yi, H. W., and Chi, Y. J. 2011. Biocontrol of Cytospora canker of poplar in north-east China with Trichoderma longibrachiatum. For. Pathol. 41:299-307.

Yoshioka, Y., Ichikawa, H., Naznin, H. A., Kogure, A., and Hyakumachi, M. 2012. Systemic resistance induced in Arabidopsis thaliana by Trichoderma asperellum SKT-1, a microbial pesticide of seedborne diseases of rice. Pest Manage. Sci. 68:60-66.

Zhang, F. G., Yuan, J., Yang, X. M., Cui, Y. Q., Chen, L. H., Ran, W., and Shen, Q. R. 2013. Putative Trichoderma harzianum mutant promotes cucumber growth by enhanced production of indole acetic acid and plant colonization. Plant Soil 368:433-444.

Zhang, S. W., Gan, Y. T., Xu, B. L., and Xue, Y. Y. 2014. The parasitic and lethal effects of Trichoderma longibrachiatum against Heterodera avenae. Biol. Control 72:1-8.

Zipfel, C. 2008. Pattern-recognition receptors in plant innate immunity. Curr. Opin. Immunol. 20:10-16. 